\title{
Hiring subsidies for people with a disability: Do they work?
}

\author{
Sergi Jiménez-Martín* Arnau Juanmarti Mestres ${ }^{\dagger}$ \\ Judit Vall Castelló
}

December 2018

\begin{abstract}
This article evaluates the effectiveness of hiring subsidies targeted to people with disabilities. By exploiting the timing of implementation among the different Spanish regions of a subsidy scheme implemented in Spain during the period 1990-2014, we employ a differencein-differences approach to estimate the impact of the scheme on the probability of Disability Insurance (DI) beneficiaries of transiting to employment and on the propensity of individuals of entering the DI program. Our results show that the introduction of the subsidy scheme is in general ineffective at incentivizing transitions to employment, and in some cases it is associated with an increased propensity of transiting to DI. Furthermore, we show that an employment protection component incorporated to the subsidy scheme, consisting in the obligation for the employer to maintain the subsidized worker in employment, is associated with less transitions to permanent employment, more transitions to temporary employment and more transitions to DI, suggesting that these type of employment protection measures can have undesired effects for people with disabilities.
\end{abstract}

JEL classification: H24; H55; J08; J14.

Keywords: Disability; Employment subsidies; Labor market transitions; Disability insurance; Difference-in-differences.

\footnotetext{
*Universitat Pompeu Fabra, Barcelona GSE and FEDEA. E-mail: sergi.jimenez@upf.edu

${ }^{\dagger}$ Centre for Research in Health and Economics, Universitat Pompeu Fabra (CRES-UPF). E-mail: arnau.juanmarti@upf.edu

${ }_{\ddagger}^{\ddagger}$ Department of Economics and Institut d’Economia de Barcelona (IEB), Universitat de Barcelona and CRES-UPF. E-mail: judit.vall@ub.edu
} 


\section{Introduction}

The proportion of working-age individuals relying on Disability Insurance (DI) benefits has increased in the last decades in many OECD countries, reaching high and sometimes unsustainable levels. In 2014, the DI beneficiary rate among working-age individuals was almost 7\% in France, 9\% in the USA, 6\% in the UK or almost $14 \%$ in Norway (OECD SOCR database). At the same time, the labor market integration of people with disabilities is very low in many of these countries; the employment rate of disabled people in OECD countries in the late-2000s was $43 \%$ (compared with an employment rate of $75 \%$ for their non-disabled counterparts). In Spain, the corresponding figures are relatively smaller: a beneficiary rate of a bit less than $4 \%$ in 2014 and an employment rate for those with a disability of $36 \%$ (compared with an overall employment rate of about $68 \%) .{ }^{1}$ These figures may underscore a high number of partially disabled individuals that can and want to work but who are unable to find a job. The reasons for this low labor market participation of disabled individuals in Spain are multiple but, for example, high unemployment rates for the general population as well as lack of information for employers on the productivity levels of disabled workers are two examples. For those individuals, DI benefits are their unique source of income and, if they do not manage to find a job, will probably continue to rely exclusively on income support programs until they enter the retirement system. This high level of dependence of disabled individuals on the DI program and their exclusion from the labor market puts an unnecessary financial pressure on the public accounts. Furthermore, it also undermines the role of work as a source of income and a route to a further integration into the society.

In view of these developments, there is a common move in several countries towards finding ways to transform a disability policy that relies too much on the role of disability benefits into an activation policy able to facilitate and promote the labor market integration of partially disabled individuals (OECD 2010). In this line, many countries are increasingly implementing policy measures aimed at promoting the employment of disabled people (OECD 2003). One of these measures, which has gained increasing importance in several countries, are employment subsidies. Employment subsidies are direct payments from the government to the employer that hires a disabled individual. In

\footnotetext{
${ }^{1}$ See Jiménez-Martín, Juanmarti and Vall (2016) for a review of DI participation trends in Spain in the last four decades.
} 
theory, these subsidies, by reducing the labor costs associated with the employment of disabled workers, increase the labor demand for these workers and, thus, their employment outcomes. The empirical evidence evaluating the effectiveness of these subsidy schemes, however, is scarce and inconclusive.

In this paper, we fill in this gap in the literature by evaluating the effectiveness of an employment subsidy scheme targeted towards the disabled implemented in Spain during the last decades, consisting in a one-time lump-sum payment granted to the employer that hires a disabled individual. In Spain, the introduction of this subsidy scheme targeting the disabled has followed a staggered implementation over time among the different Spanish regions (Autonomous Communities ${ }^{2}$ ). We exploit this staggered implementation at the regional level to develop a difference-in-differences strategy in order to estimate the effect of the subsidy scheme on the employment outcomes of the targeted disabled population. We use rich administrative data provided by the Spanish Social Security Administration to model employment transitions of all DI beneficiaries over the period 1990-2014. We then estimate the effect of the introduction of the subsidy scheme on the probability of DI beneficiaries of finding a job under each of the subsidized employment types. It is important to note that individuals in the DI system in Spain are allowed to combine the benefits with a job (while receiving the full amount of benefits) if they are categorized as partially disabled individuals (that is, if they keep some capacity to work). More than half of DI beneficiaries in Spain fall in this category. Furthermore, some DI beneficiaries in the total disability system are also observed as working although employment rates are much smaller for this group of individuals.

Our results show that, in general, the subsidy scheme is ineffective at incentivizing transitions to each of the types of employment subsidized (temporary employment, permanent employment and conversions from temporary to permanent employment), although we find significant effects of some of the subsidies in specific population subgroups. In particular, subsidies promoting permanent employment are effective at increasing transitions to both temporary and permanent employment for older individuals, and subsidies incentivizing conversions from temporary to permanent employment are effective at promoting that type of conversions for women. One important difference in the three types of employment subsidies that we consider is the fact that, for the case of

\footnotetext{
${ }^{2}$ Autonomous Communities are the 17 regions that conform the first level of administrative decentralization in Spain
} 
permanent employment, there is a national subsidy in place for the entire duration of our sample, which is not the case for the other two types of subsidies. Therefore, for the case of permanent employment, regional subsidies add up to the baseline national subsidy and our estimates capture changes at the intensive margin. For subsidies incentivizing temporary employment and conversions from temporary to permanent employment our estimates can be interpreted as extensive margin results.

The subsidy scheme incorporates an element of employment protection, consisting in the obligation for the employer to maintain the subsidized worker in employment during a certain amount of time if hired under a permanent contract. Although we show that this measure is effective at protecting subsidized workers against unemployment once they are hired, our results show that, for unemployed individuals, a higher degree of employment protection is associated with a decrease in the probability of being hired under a permanent contract and an increase in the probability of being hired on a temporary basis. These results suggest that employment protection measures of this type may harm the chances of disabled individuals of finding permanent employment in the first place and are indicative that incorporating employment protection measures to subsidy schemes may undermine the effectiveness of the subsidies at incentivizing transitions to employment.

Because hiring subsidies have in theory a direct influence on the employment prospects of the targeted population, they may affect the decision of partially disabled individuals that are considering the possibilities of whether to work or to turn to Disability Insurance (or both). Because reducing the dependence of the disabled on DI is a policy aim in most countries and an indirect objective of employment measures targeted to people with disabilities, in this paper we also investigate the effect of the subsidy scheme on the propensity of individuals to enter the DI program. Our results show that both the introduction of the subsidy scheme and a higher degree of employment protection are associated with an increase in the transition rate to DI. Most importantly, we see that these disincentive effects of the employment protection component are concentrated in younger individuals and men, groups for whom a higher degree of employment protection is associated with higher transitions to disability insurance, suggesting that this protection measure may be inducing individuals that are looking for permanent employment to turn to DI instead. According to the Spanish Ministry of Employment and Social Security 557,68 million Euros were spent on these subsidies in 2015. Thus, it is important to understand the effects of this policy as it represents an important budgetary cost.

The rest of the paper is organized as follows; Section 2 provides a brief overview of the literature on the topic while Section 3 describes how hiring subsidies are organized 
in Spain. Section 4 explains the data used and Section 5 outlines the empirical strategy. Finally, section 6 reports the results of the estimation and Section 7 concludes.

\section{Literature on Disability and Employment}

Due to the strong increase in the proportion of working-age individuals entering the DI system, many empirical papers have focused on the effectiveness of policies that reduce DI inflows and/or promote employment of those disabled individuals that keep some capacity to work (partially disabled). In this line, there is a growing literature that investigates the effect on DI (and employment) participation of particular characteristics of the DI system such as the eligibility criteria or the degree of screening stringency (Gruber and Kubik 1997; Autor and Duggan 2003; De Jong, Lindeboom and van der Klaauw 2011; Staubli 2011; Johansson, Laun and Laun 2014), the generosity of the system (Marie and Vall Castelló 2012), or particular policies providing financial or in-kind work incentives to DI beneficiaries (Moffit and Hoynes 1999; Autor and Duggan 2006; Adam, Bozio and Emmerson 2010; Benítez-Silva, Buchinsky and Rust 2010; Kostol and Mogstad 2014). The Netherlands, for example, introduced several policies during the 90's to try to reduce the inflow into the DI system as well as to promote employment of disabled workers. In a review paper, Koning and Lindeboom (2015) explain that the Dutch experience shows that changes in the screening process and increased employer incentives have proven to be very efficient in keeping employees working and decreasing inflows into the DI system. On the contrary, changes in the duration and level of disability benefits seem to be less effective. Thus, in this context, employment subsidies represents an additional policy that has been relatively unexplored in the literature but that can potentially be effective in promoting employment of disabled individuals. To the best of our knowledge, there are only five studies evaluating employment subsidy schemes targeted to disabled individuals. Two of them use experimental approaches to evaluate the effect of disclosing entitlement to a subsidy scheme on the probability of receiving a call-back. Deuchert and Kauer (2013) show that disclosing entitlement to the subsidy scheme has no significant effect on the proportion of call-backs received. A similar exercise is undertaken by Baert (2016), who reports that call-back rates were significantly lower for disabled applicants (as compared to non-disabled applicats) and this difference is not affected by the disclosure of entitlement to the subsidy scheme.

The other three studies on employment subsidies for disabled individuals exploit natural experiments that introduce (or reform) a particular subsidy scheme for the disabled. Datta Gupta and Larsen (2010) exploit plausibly exogenous variation arising from the 
introduction of the Danish Flexjob Scheme and find that it increases employment probabilities of treated individuals by 33 percentage points. In a more recent paper, Datta Gupta, Larsen and Thomsen (2015) evaluate the effect of a reduction in the amount of the subsidy of the same program (the Danish Flexjob Scheme) and they find that the reduction in the subsidy increased the proportion of new hires that came from within the same firm (relative to those that came from unemployment). They argue that the reduction in the financial incentives to hire disabled workers makes employers less willing to take the risk of hiring individuals and more prone to resort to employees with a revealed productivity level.

Finally, Vall Castelló (2012) evaluates a reform in a Spanish program that provides deductions to the Social Security contributions for employers that hire disabled individuals. The reform raised the amount of the deductions available when hiring disabled women. She finds that the reform resulted in a significant increase in employment probabilities of disabled women ${ }^{3}$.

A problem with these previous studies evaluating subsidy schemes targeted to the disabled is the existence of large opposing results, with experimental studies finding no effects of the subsidy schemes on employment of the disabled, and observational studies (using difference-in-differences approaches) finding significant and sometimes very large effects. In our understanding, there are at least two issues that affect the internal and external validity of those studies which may be contributing to those large differences. First, most of the studies (both observational as well as experimental) are limited to specific and sometimes narrow groups of disabled individuals (a group of adolescents at the end of a vocational education and training program, a group of clients of job coaching services, long-term disabled without loss in working capacity and women). Second, experimental studies are only able to evaluate the effects on the first stage of the recruitment process (call-back rates).

In this paper, we contribute to this literature on several dimensions. First, by using a large administrative dataset provided by the Social Security Administration, we are not limited to specific population subgroups and are able to evaluate the effect of the subsidy scheme on (a representative sample of) all the population of DI beneficiaries. Covering

\footnotetext{
${ }^{3}$ There are other studies that evaluate the effect of employment subsidies implemented also in Spain, but they are focused on subsidies targeted to the general population. See, for example, García-Pérez and Rebollo (2009); Hernanz, Jimeno and Kugler (2003) and Arellano (2005)
} 
all DI beneficiaries also contributes to the generalization of our results. Second, the use of panel data allows us to estimate the effect of the subsidies on transition rates to employment (the probability of being hired), which is the direct outcome that this type of subsidies are trying to incentivize.

Third, we examine the effects of a previously unexplored component of employment protection in the context of disabled workers: the obligation for the employer to maintain the subsidized worker in employment for a certain amount of time. In general, previous studies have shown that employment protection legislation that imposes firing costs on the employer may harm the employment outcomes of the protected populations, specially in the case of the youth (see Burtless (1985) for a seminal paper on the topic or Skedinger (2011) for a relatively recent review of studies). In the case of the disabled, a set of papers have shown that the Americans with Disabilities Act (ADA) in the US, a law that requires employers to provide accommodations for disabled workers and prohibits employment discrimination on the grounds of disability, has indeed decreased the employment rates of the disabled (De Leire 2000; Acemoglu and Angrist 2001). In this paper, we contribute to previous literature by analyzing the consequences of incorporating employment protection measures in subsidy schemes for disabled workers.

Finally, to the best of our knowledge, this is the first study that analyzes the effect of employment subsidies for the disabled on the propensity of individuals to participate in DI. Given the concerns about increases in DI inflows in developed countries, the potential effects of employment promotion policies on DI inflows is a crucial point.

\section{Employment Subsidies for People with a Disability in Spain}

In 1981 two types of employment subsidies targeted to disabled individuals were introduced in Spain ${ }^{45}$. First, the law established deductions to the Social Security contributions that employers had to pay for the employment of a disabled individual. The deductions amounted to $70 \%$ for disabled individuals who were less than 45 years old and $80 \%$ for disabled individuals who were 45 or older. Second, the law established a lump-sum one-time subsidy (hereafter, hiring subsidy) of 1803 euros granted to the employer at the time that he/she hires the disabled individual. To be entitled to these

\footnotetext{
${ }^{4}$ Royal Decree 1327/1981.

${ }^{5}$ In this paper, we focus on employment subsidies in the ordinary private market. We do not analyze employment subsidies for disabled individuals that are employed in companies of sheltered employment.
} 
subsidies the individual needs to have a degree of disability of $33 \%$ or more as proved in the disability certificate ${ }^{6}$. If you are receiving a disability benefit (which is only available for individuals with a disability degree of $33 \%$ or more) you are also entitled to receive the employment subsidy. Furthermore, the subsidies were only available for permanent contracts.

From the late 1990's, Spain has implemented a process of progressive decentralization of the active labor market policies to the regions (there are 17 regions, Autonomous Communities, in Spain). In 1997 and 1999 two important labour market reforms fostered the decentralization process of active labour market policies. Therefore, regions have modified or extended the subsidy scheme that was implemented at the national level. Importantly, as regions cannot legally modify the structure of Social Security programs, the decentralization process has been limited to the hiring subsidies. Thus, the scheme providing deductions to Social Security contributions has been identical in all regions since its first national implementation in 1981. Therefore, regions have progressively (1) extended the hiring subsidies to foster two other forms of employment (temporary employment and conversions from temporary to permanent employment) and (2) increased the amount of each type of subsidy, often making it conditional on the gender and/or the degree of disability of the individual. The reasons for some regions introducing the scheme at one particular point in time are mainly political; regions in Spain have different political cycles and regional elections are celebrated at different point in times.

As a result, the hiring subsidy presents variation over the different regions that can be exploited to evaluate the effect of the scheme. There are three types of subsidies: subsidies incentivizing temporary employment for unemployed individuals; subsidies incentivizing permanent employment for unemployed individuals; and subsidies incentivizing conversions from temporary to permanent employment. We have collected information on the availability of each of these types of subsidies in each region from 1990 to 2014. If the subsidy was available in a particular region and time period, we have also recoded the most important characteristics of the scheme (amount of the subsidy, length of employment protection, etc.). Most importantly for our purposes, the introduction of each of these three types of subsidies has been progressive over time in the different regions. To

\footnotetext{
${ }^{6}$ The disability certificate is the main administrative recognition of a disability in Spain, and provides access to several rights and services. Individuals are assessed by a technical team, which determines the condition of disability and assigns a degree of severity ranging from $33 \%$ to $100 \%$.
} 
visualize the evolution in the timing of implementation over the different regions, Figure 1 shows, for each type of subsidy, a time series of the number of regions implementing the subsidy over the period 1990-2014. As can be seen, there is a gradual increase in the number of regions implementing the scheme. It has to be noted that, in the case of hiring subsidies for permanent employment, the subsidy is implemented at the national level during our study period and we consider a region as implementing this subsidy only when the amount of the subsidy in the region is higher than the amount implemented at the national level. Therefore, to be precise in this case we are estimating the effect of a more generous subsidy. As the labour market reforms of 1997 and 1999 accelerated the decentralization process of active labour market policies, we can see in Figure 1 that most of the regional policies for disabled individuals started from the year 2000. It is also important to note that subsidies for conversions from temporary to permanent employment do not vary after 2006. Therefore, for this outcome, all the variation comes from the years 2000 to 2006 .

To gauge the importance of the subsidies, Figure 2 presents a time series of the mean amount of each type of subsidy for the regions that do implement the subsidies over the period 1990-2014, and Figure 3 presents a time series of the percentage that amount represents out of the disabled annual wages. The mean amount over our analysis period of the subsidies incentivizing permanent employment of unemployed individuals is 4597 euros, which represents a $28 \%$ out of the annual wages of disabled permanent employees. For the subsidies incentivizing temporary employment, the mean amount is 1555 euros, $11 \%$ of the annual wages of disabled temporary employees. For the subsidies incentivizing conversions from temporary to permanent employment, the mean amount is 3948 euros, $24 \%$ of the annual wages of disabled temporary employees.

The subsidy scheme incorporates an important element that provides employment protection to the individuals hired under the scheme. For the individuals that are hired on a permanent basis (either from unemployment or from temporary employment), the scheme obliges the employer to maintain the subsidized worker in employment during a certain amount of time. If the employer fires the worker, he/she has to reimburse the subsidies received when the hiring took place. We cannot exploit differential timing of implementation of this measure because it has been in place since the first introduction of the scheme at the national level in 1981 . We can, however, exploit regional variation in the intensity of the protection. In 1981 the employment protection measure required employers that hired a disabled individual on a permanent basis to maintain the subsidized worker during three years. However, some regions have changed the length of employment protection that applies in their territories. Figure 4 shows a time series of 
the different lengths of employment protection implemented by the different regions during the period 1990-2014, which ranges from 5 quarters to 20 quarters $^{7}$

\title{
IV. Data, Samples and Descriptive Evidence
}

\begin{abstract}
A. Data
We use the Continuous Sample of Working Lives (CSWL), which is an administrative dataset constructed by the Spanish Social Security Administration from its official contributory register data of individuals. In each wave from its design in 2004 until the current year, the dataset contains information for a $4 \%$ sample of all the individuals that in that year contributed to the Social Security Administration (either by working or by receiving unemployment benefits) or that were receiving contributory benefits (old age, survivor or disability benefits) ${ }^{8}$. For each of these individuals, it is possible to reconstruct his/her entire contributory history from his/her first day of contribution. The information provided contains the particular characteristics of the employment situation of the individual if he/she is working (type of employment contract, sector of employment, characteristics of the firm such as number of employees or type of legal status, contributory group, etc.), the particular characteristics of the unemployment situation if he/she is unemployed (type and amount of the unemployment benefit, etc.), the characteristics of his/her beneficiary status if he/she is receiving contributory benefits (type and amount of the benefit, etc.) and demographic characteristics such as age, gender and education level. Furthermore, because this information is available for each individual for his/her entire contributory history, it is possible to construct variables that can capture in a precise way the past labor market experience of that individual in any particular point in time.

For each year wave, therefore, the dataset contains information on a $4 \%$ sample of all the individuals that in that year have a relationship with the Social Security administration. We have taken all DI beneficiaries that can be found in year waves from 2007 to 2014 and have reconstructed their entire contributory histories from 1990. Then, on the
\end{abstract}

\footnotetext{
${ }^{7}$ Figure 4 plots, for every observed quarter, the number of quarters of protection in place taking into account all variation across regions in that particular quarter. It does not show, however, the number of regions implementing them as the aim of the picture is to show the variation of this variable in each quarter during our sample period.

${ }^{8}$ For example, in 2014 there are 1178730 individuals included in the CSWL
} 
basis of the observed as well the retrospective information we have constructed a panel of quarterly transitions from the first quarter of 1990 to the fourth quarter of 2014. The resulting panel contains periodic information on their employment situation, the characteristics of their DI status, and demographic characteristics, from which we will identify and model quarterly employment transitions ${ }^{9}$. From this panel, we construct two separate samples, according to the target population of each type of employment subsidy studied. On the one hand, for the subsidies incentivizing temporary or permanent employment of unemployed individuals, we construct a sample containing all unemployed DI beneficiaries in each time period, in which we will model transitions from unemployment to either temporary or permanent employment. On the other hand, for the subsidies aimed at promoting the conversion from temporary to permanent employment, we construct a sample of all the DI beneficiaries that are working under a temporary contract in each time period, from which we model the transitions from temporary employment to either permanent employment or to unemployment.

Finally, to evaluate the effect of the subsidy scheme on the propensity of individuals of transiting to DI, we use the CSWL to construct a representative sample of the population (both disabled and non-disabled individuals). To that end, we take a representative 5\% of non-DI beneficiaries present in any of the year waves 2007-2014 and reconstruct their contributory histories from their first day of contribution. We then add these individuals to our panel of DI beneficiaries (but before getting the benefit) to form a quarterly panel consisting of a representative sample of the population from the first quarter of 1990 to the fourth quarter of 2014, from which we model transitions to DI (see columns 5 and 6 in Table 2). Regressions will be estimated using weights in order for the non-disabled individuals in the panel to represent their actual proportion in the original sample.

\section{B. Samples}

The sample of unemployed individuals consists of 1170894 observations (44780 individuals) distributed along the one-hundred quarters that form our study period (from the first quarter of 1990 to the fourth quarter of 2014) $)^{10}$. The sample of temporary employees consists of 66579 observations (9373 individuals) and the sample of non-disabled

\footnotetext{
${ }^{9}$ An individual enters the panel in the moment he/she starts receiving DI benefits

${ }^{10}$ See columns 1 and 2 of Table 2 for descriptive statistics of this sample
} 
individuals consists of 5646966 observations (103564 individuals) ${ }^{11}$. Each sample is restricted to working-aged individuals (individuals aged 16-64) and we have excluded from the samples of DI beneficiaries individuals classified with the highest degree of disability (severely disabled) ${ }^{12}$, as they are strongly incapacitated for working. As expected, in Table 2 we can see that the sample of non-disabled individuals is much younger than the samples of disabled individuals. It is important to note that in the CSWL it is not possible to identify if an individual is actively looking for a job. We observe whether the individual is receiving unemployment benefits, but this is not sufficient to identify the condition of activity because there are individuals that are not receiving unemployment benefits but who are looking for a job. Therefore, our sample of unemployed individuals includes also inactive individuals who are not actively looking for a job. This observation is important, because in general, one of the conditions imposed by the different regions to be eligible for the subsidy schemes is to be registered as a job seeker in a public employment agency. However, this should not affect our results mainly for two reasons: first, all individuals registered in an employment agency will be identified as unemployed in our sample and second, inactive individuals have strong incentives to register as job seekers because of the existence of the hiring subsidies.

It is also worth commenting on how the subsidy scheme specifies the eligibility criteria in terms of the disability condition of the individual. In general, regions specify that subsidies are granted to individuals with a disability certificate with a degree of disability of at least a 33\% (see section III). Here, we evaluate if hiring subsidies are effective at incentivizing employment transitions of DI beneficiaries, and with our data we cannot identify if an individual is in possession of a disability certificate. However, this fact should not affect our results. First, in many of the cases, the subsidy schemes specifically indicate that individuals that are receiving disability benefits are also eligible. Second, in Spain DI beneficiaries are by law automatically entitled to have a disability certificate and receive all rights and services it entails, including therefore the right to be eligible for the hiring subsidies (even if this is not specifically indicated in the subsidy scheme).

\footnotetext{
${ }^{11}$ See columns 3 and 4 of Table 2 for descriptive statistics of the sample of temporary employees and columns 5 and 6 for descriptive statistics of the sample of non-disabled

${ }^{12}$ The Social Security establishes three degrees of disability according to the reduction in the working capacity lost by the individual as a result of the disability: partial disability, total disability and severe disability. These degrees, in turn, affect the amount of the benefit the individual receives.
} 


\section{Descriptive Evidence}

In this section we review key facts about the transitions of unemployed DI beneficiaries to either temporary or permanent employment and the transitions of DI beneficiaries in temporary employment to a permanent employment position, which are the transitions that the subsidy scheme is intended to incentivize. Although in this paper we evaluate the effectiveness of hiring subsidies targeted to disabled individuals on the transitions to employment of the targeted disabled population, for comparative purposes in this section we also provide descriptive statistics for a sample of non-disabled individuals. Figure 5.A presents the evolution over time of the transition rates from unemployment to both temporary and permanent employment for disabled and non-disabled individuals, and Figure 5.B shows the same transition rates in the year 2014 differentiated by region. A crucial observation is that there is substantial variation across regions in the transition rates to both temporary and permanent employment, variation that seems even more pronounced for disabled individuals. In this paper, we analyze if these regional differences can be accounted for by differences in hiring policies across regions ${ }^{13}$.

Figure 6 explores the same dimensions than Figure 5 but in relation to the conversion rate from temporary to permanent employment. Figure 6.A presents the evolution over time of contract conversions for both disabled and non-disabled individuals. Note that the aggregate trends are almost identical for both populations, which may be an indication that the disabling condition plays no role in hiring decisions once the individual is employed, probably because of a reduction in the uncertainty faced by the employer regarding the productivity of the disabled worker. In turn, this may suggest that there is no necessity to provide incentives targeted to disabled workers once they are employed. In Figure 6.B we see that there are also large differences across Spanish regions in the conversion rate from temporary to permanent employment. Again, in this paper we analyze if these differences are the result of differences in hiring policies across regions.

\footnotetext{
${ }^{13}$ In Figure 5.B we can see that the transition rate is higher for the Balearic Islands region (IB). This is due to the fact that the Islands have additional employment promotion measures specifically targeted to the disabled. However, these additional measures remain constant over time during our sample period and will be captured by the regional fixed effect in our model
} 


\section{Empirical Strategy}

\section{A. Transitions to Employment Alternatives}

Our aim is to estimate the effect of the hiring subsidies on the probability of the disabled targeted population of finding a job under each of the subsidized employment types (either temporary or permanent employment for unemployed individuals and conversions from temporary to permanent employment for temporary employees). We use a competing risk multinomial logit approach to model the transitions of DI beneficiaries to the different employment alternatives. Then, for each of the three types of subsidies, we exploit the staggered implementation of the scheme among regions to estimate difference-in-differences style regressions of the form:

$$
\begin{array}{r}
P_{i t r}^{j}=\beta_{0}^{j}+\beta_{1}^{j} \text { HiringSubsidies }_{t r}+\beta_{2} \text { Quartersof Protection }_{t r}+\beta_{3}^{j} X_{i t r}+\delta_{t}^{j}+\gamma_{r}^{j}+ \\
+\sum_{r=1}^{17} \eta_{r}^{j} \text { Region }_{r} \text { Trend }_{t r}+\alpha^{j} U R_{t r}+v_{i t r}^{j}
\end{array}
$$

Where $P_{i t r}$ is the logarithm of the ratio of the probability of transiting to a particular employment alternative over the probability of remaining in the current state, and $\mathrm{j}$ refers to a particular employment alternative. Because the different types of subsidies apply to different populations, two different types of models are estimated. For the subsidies incentivizing temporary or permanent employment for unemployed disabled individuals, the model is estimated on our sample of unemployed disabled individuals, and in this case $j=(u t, u p)$, where $u t$ refers to the alternative in which the individual transits from unemployment to temporary employment and $u p$ to the alternative in which the individual transits from unemployment to permanent employment. In this case, the base category corresponds to the alternative in which the individual remains in unemployment. For the subsidies encouraging conversions from temporary to permanent employment, the model is estimated on our sample of temporary employees, and in this case $j=(t p, t u)$, where $t p$ refers to the alternative in which the individual transits from temporary employment to permanent employment and $t u$ to the alternative in which the individual transits from temporary employment to unemployment. In this case, the base category corresponds to the alternative in which the individual remains in temporary employment.

In each model, subscript $i$ refers to a particular individual, subscript $t$ to a particular time period and subscript $r$ to a particular region. HiringSubsidies $s_{t r}$ is an indicator variable equal to 1 for regions and time periods in which the particular subsidy scheme is available. Therefore, $\beta_{1}^{j}$ captures the effect of the introduction of the hiring subsidies on 
the transition rate to each of the employment alternatives. All models include year fixed effects $\left(\delta_{t}^{j}\right)$ to control for specific reforms of the subsidy schemes implemented at the national level as well as for other national policies. They also include region fixed effects $\left(\gamma_{r}^{t}\right)$ to control for region specific factors such as other disability policies implemented at the regional level. To control for potential differential pre-trends over the different regions, regressions include region-specific linear time trends $\left(\right.$ Region $_{r}$ Trend $_{t r}$ for each region). Regressions also include the unemployment rate in each region and time period $\left(U R_{t r}\right)$ to control for differential business cycle shocks. Standard errors are clustered at the region level to deal with serial correlation (Bertrand, Duflo and Mullainathan 2004).

We additionally include in the models a set of individual time-varying predetermined covariates $\left(X_{i t r}\right)$ that control for demographic characteristics of the individuals, for characteristics of their disability status, for characteristics of their unemployment or employment situation and for their degree of labor market experience. Table 1 provides a description of all the individual and aggregate controls included in the regressions and Table 2 provides descriptive statistics of these variables for our estimation samples.

Finally, Quartersof Protection tr $_{\text {is }}$ used to measure the effect of the employment protection component of the subsidy scheme. For each region and time period, the variable measures the number of quarters the individual must be maintained in employment if hired on a permanent basis. Therefore, $\beta_{3}^{j}$ measures the effect of an additional quarter of employment protection on the transition rate to each of the employment alternatives.

We believe that our empirical strategy is able to isolate the causal impact of employment subsidies on labor market transitions of disabled individuals for several reasons: First, we are able to include several controls both at the regional as well as at the national level that will account for the impact of other elements on the labor market outcomes of the disabled. Second, there is no observable pattern of certain regions introducing the employment subsidies at the same time. Instead, the introduction of the subsidies is pretty staggered across time and across regional units. Finally, as we are distinguishing between the impacts of three different types of subsidies (to permanent or temporary employment as well as conversions from temporary to permanent) this provides us with further elements to believe that we are indeed capturing the impact of each specific policy tool on the specific labor market transition targeted in each of the three cases.

\section{B. Transitions to Disability Insurance}

To evaluate the effect of the subsidy scheme on the probability of entering to the DI program, we estimate the same specification applied to the sample of non-disabled individuals. In this case, we are interested in estimating the effect of the hiring subsidies on 
the transition rate to DI, and therefore we estimate a linear probability model. That is, our model reduces to a binary discrete choice model, where the dependent variable is a dummy variable that takes the value one if the individual transits to the DI program between time periods $t-1$ and $t$. In this case, our difference-in-differences style specification is the following:

$$
\begin{array}{r}
Q_{i t r}=\varphi_{0}+\varphi_{1} \text { HiringSubsidies }_{t r}+\varphi_{2} \text { Quartersof Protection }_{t r}+\varphi_{3} X_{i t r}+\delta_{t}+\gamma_{r}+ \\
+\sum_{r=1}^{17} \eta_{r} \text { Region }_{r} \text { Trend }_{t r}+\alpha U R_{t r}+v_{i t r}
\end{array}
$$

In this context, we consider several specification alternatives varying the type of hiring subsidy included in the specification. As stated above, regressions will be estimated using weights in order for the non-disabled individuals in the panel to represent their actual proportion in the original sample.

\section{Results}

\section{A. Effect of Hiring Subsidies on Transitions to Employment}

Table 3 shows the results of the estimation of the multinomial logit models evaluating the effect of hiring subsidies on the transitions to employment. The different columns show the model estimated for each type of subsidy (subsidies incentivizing temporary employment of unemployed individuals, subsidies incentivizing permanent employment of unemployed individuals, and subsidies incentivizing conversions from temporary to permanent employment). We only show the coefficients on the policy variables of interest, that is, the dummy variable indicating the availability of hiring subsidies and the variable indicating the number of quarters the employer has to maintain the subsidized worker in employment if hired on a permanent basis (quarters of protection). We show the effects on the relative risk ratios (RRR) and the marginal effects on the predicted probabilities ${ }^{14}$ The marginal effects are calculated at the means of all covariates and ex-

\footnotetext{
${ }^{14}$ Relative risk ratios are the ratios between the probability of transiting to each of the employment alternatives and the probability of remaining in the corresponding employment state (base category). Marginal effects refer to the direct effect on the predicted probability of transiting to the corresponding employment alternative.
} 
pressed as percentage increases in the respective transition probabilities. In particular, for the subsidy variable, the marginal effect refers to the percentage increase in the respective transition probability that results from the introduction of the corresponding type of subsidy. For the quarters of protection, the marginal effect refers to the percentage increase in the respective transition probability that results from one additional quarter of employment protection.

We can see in Table 3 that none of the coefficients on the subsidy variables are statistically different from 0 , indicating that the introduction of any of the subsidy schemes has no impact on the transition rate to the types of employment they try to incentivize. We do find, however, a significant effect of the employment protection component of the subsidies. In particular, for unemployed individuals (columns 1 and 2), a longer period of obligation for the employer to maintain the subsidized worker in employment if hired on a permanent basis is associated with more transitions to temporary employment and less transitions to permanent employment. Controlling for the existence of subsidies incentivizing permanent employment (column 1), an additional quarter of protection is associated with a significant $1.08 \%$ increase in the probability of being hired under a temporary contract. Controlling for the existence of subsidies incentivizing temporary employment (column 2), an additional quarter of employment protection is associated with a significant $0.91 \%$ increase in the transition rate to temporary employment and with a significant $1.58 \%$ decrease in the probability of being hired with a permanent contract.

These results suggest that imposing difficulties for employers in their freedom to terminate a permanent employment relationship induces them to hire less disabled individuals on a permanent basis in the first place, and incentivizes them to hire the individual on a temporary basis instead. Therefore, this type of employment protection measure reduces the chances of disabled individuals of achieving a permanent employment position and makes them work on a temporary basis, something probably less attractive for them due to the higher instability and often worse working conditions of this type of employment. In fact, there is recent evidence for Spain that temporary contracts reduce the number of days worked (by 4.9\%) and earnings (by 9.8\%) for low skilled men in the first 10 years of labour market experience (Garcia Perez et al, 2018). Of course, the main objective of this measure is to protect disabled workers against unemployment and incentivize longer employment relationships, possibly offering protection against unfair dismissal or discrimination on the grounds of disability. To see if the measure is effective in this regard, we investigate if it actually protects already employed workers against unemployment. Using the CSWL, we construct a panel of permanent employees during our study period (1990-2014). In the data we can see if the employee has a contract that 
specifically recognizes that he/she is disabled (a disability contract). This type of contract is designed to recognize the disability condition of the employee and entitles them to benefit from the hiring subsidy. Therefore, all disabled employees that where hired under the subsidy scheme will have a disability contract. Using the sample of permanent disabled employees, we estimate the effect of having a disability contract on the probability of permanent disabled employees of transiting to unemployment. The results are presented in Table 4. Indeed, having a disability contract reduces the probability of transiting to unemployment by 3.5 percentage points, a reduction of $28.5 \%$ in the transition rate to unemployment with respect to employees without a disability contract (that have a 12.25 pp probability of transiting to unemployment).

These results suggest that the employment protection component of the subsidy scheme is actually effective at protecting workers against unemployment once they are hired. However, the net results of this measure are unclear because we have shown above that it reduces the chances for unemployed individuals of being hired in the first place. In addition, it could be the case that tying this type of protection measure to the subsidy scheme is undermining its effectiveness at incentivizing transitions to employment, contributing to the lack of effect that we find. Unfortunately, because the employment protection component of the subsidy scheme is present in all regions and time periods of our analysis, we are unable to analyze the direct impact of the measure on the effectiveness of the subsidy scheme at incentivizing transitions to employment. However, the evidence we provide regarding the negative effect of a higher degree of employment protection on the probability for disabled individuals of finding a permanent employment is indicative that the measure may indeed play an important role in explaining the ineffectiveness of the subsidy scheme.

Because the results for the general population of DI beneficiaries presented above may underscore differences among particular subgroups, we provide the results differentiated by age and gender in Tables A1 and A2 in the Appendix section. We can see that the hiring subsidies are ineffective at incentivizing transitions to employment for individuals until age 50 but they proof to be effective for the older group of workers aged 51-64 (see panel C). In particular, the introduction of the subsidies incentivizing permanent employment for unemployed individuals increases the probability of transiting to temporary employment by $10.6 \%$ and the probability of transiting to permanent employment by $33.27 \%$. Notably, in this case in which the hiring subsidies are effective, the employment protection component does not have a significant effect on the transition rates to the types of employment incentivized.

With respect to gender differences, we can see in Table A2 that subsidies incentivizing 
conversions from temporary to permanent employment have a strong positive and significant impact for women, with the introduction of the subsidy increasing the conversion rate by $81.5 \%$.

Finally, in Table A5 we estimate a placebo regression using data from 1990 to 2000, when there are no regional subsidies in place. The way in which we produce the fake policies is, for each policy in each region, we randomly assign a lag of between 1 and 10 years. As it can be seen in Table A5, most of the coefficients are insignificant except the one for transitions to permanent employment. As it can be inferred by the big coefficient and the big standard error of that value, this is due to the small number of transitions for observations before 2000; only $0.1 \%$ of the observations before 2000 do report a transition to permanent employment (precisely because there are no regional policies in place to foster these transitions). Therefore, if our simulated fake policy coincides in years and regions with the lowest number of transitions to permanent employment, then we get this huge coefficient which is clearly out of range. Apart from that, the rest of results are non-signficant, which provides credibility to our baseline findings.

\section{B. Effect of Hiring Subsidies on Transitions to Disability Insurance}

In theory, hiring subsidies, by affecting the employment possibilities of the disabled, may in turn affect their propensity to participate in the disability insurance scheme. For a partially disabled individual that is dealing with the decision of either working or turning into disability insurance (DI), an improvement (or worsening) of their chances of finding employment may play an important role in his/her decision to participate in DI. For this reason, in this section we investigate the effect of the subsidy scheme on the propensity of individuals of entering the DI program. We estimate the same models as before in a sample of non-disabled individuals, looking at the effect of both the introduction of the hiring subsidies and the intensity of the employment protection component on the probability of non-disabled individuals of transiting to the DI program (on the transition rate to DI).

Table 5 presents the estimation results for the whole sample of non-disabled individuals, while Tables A3 and A4 in the Appendix section present the results differentiated by age and gender, respectively. In the regressions, the transition rate to DI is expressed as the number of transitions to DI per 1000 individuals. For the whole sample (Table 5), we find that the introduction of the hiring subsidies incentivizing conversions from temporary to permanent employment increases the transition rate to DI by 0.065 for every 1000 individuals (which corresponds to an increase in the transition rate to DI of 5.34\%). We also find that an increase in the intensity of the employment protection component is 
associated with more transitions to DI. In particular, an additional quarter of protection is associated with an increase in the transition rate to DI of 0.004 for every 1000 individuals (which corresponds to a $0.35 \%$ increase in the transition rate to DI).

We also find significant effects and important differences in the results when differentiating by age and gender. In particular, we find that the introduction of the hiring subsidies incentivizing permanent employment significantly increases the transition rate to DI for younger individuals (ages 16-35) as well as for men. We also find a positive and significant effect on the transition rate to DI of the introduction of the subsidies incentivizing conversions from temporary to permanent employment in the case of older individuals (ages 50-64).

Regarding the employment protection component of the subsidy scheme, we show that a longer time period of obligation to maintain the subsidized worker in employment is associated with a higher transition rate to DI for individuals aged 16-35 and for men.

These results, therefore, seem to suggest that the employment protection component is inducing disabled individuals that are looking for a permanent employment position to turn to DI instead.

\section{Conclusions}

The high level of dependence of disabled individuals in the Disability Insurance program and their low attachment to the labour market is prompting many developed countries to design and implement policies specifically targeted to promote higher levels of employment among the disabled population. There are, however, few empirical studies evaluating the effectiveness of particular policies and, therefore, little information on which types of measures are effective at increasing employment participation among disabled people.

In this paper, we contribute to fill in this information gap by evaluating the effectiveness of an employment promotion measure targeted to disabled individuals implemented in Spain during the last decades, consisting in one-time lump-sum subsidies granted to the employer that hires a disabled individual. We use rich administrative data to model employment transitions of DI beneficiaries. Then, we exploit the staggered implementation of the subsidy scheme among the different Spanish regions to design a differencein-differences approach in order to estimate the effect of the hiring subsidies on the transition rate of DI beneficiaries to each of the types of employment subsidized (temporary employment, permanent employment and conversions from temporary to permanent employment). 
Our results show that the subsidy scheme is in general ineffective at incentivizing transitions to employment, although we find positive and significant effects in some cases. In particular, the hiring subsidies are effective at incentivizing transitions to temporary and permanent employment for unemployed older individuals and at incentivizing conversions from temporary to permanent employment for women.

We also evaluate the effect of an employment protection component associated with the subsidy scheme, consisting in the obligation for the employer to maintain the subsidized worker in employment during a certain amount of time if hired on a permanent basis. By exploiting variation over the different regions in the length of time of employment protection required for the employer, we show that a higher degree of employment protection is associated with a decrease in the probability of being hired under a permanent contract and an increase in the probability of being hired on a temporary basis. Although we show that this measure is effective at protecting subsidized workers against unemployment once they are hired, the net results are unclear if it prevents unemployed individuals of being hired in the first place, or forces them to resort to temporary employment, with the higher instability and worse working conditions that often characterizes this type of employment. Furthermore, these results are indicative that tying these type of protection measures to subsidy schemes may undermine their effectiveness at incentivizing transitions to employment. This result is in line with an extensive literature in labour economics showing that higher employment protection leads to lower hiring probabilities (see for example Bentolila et al. 1994, Bentolila et al. 1990 or, more recently, Sestito et al. 2018).

Finally, we investigate if the subsidy scheme has an effect on the propensity of nondisabled individuals of entering the DI program. Our results show that the introduction of the subsidy scheme increases the transition rate to DI for younger individuals (ages 16-35) and for men. Furthermore, we find that a higher degree of employment protection is also associated with a higher transition rate to DI for the same individuals, for whom the employment protection component is associated with higher transitions to temporary employment, suggesting that some individuals may be induced to turn to DI because of difficulties to find permanent employment caused by the effects of the employment protection measure.

We believe our results have important policy implications as a non-negligible amount of money (557,68 millions Euros in 2015 in Spain) are spent in these policies every year. 


\section{REFERENCES}

Acemoglu, Daron and Joshua D. Angrist. 2001. "Consequences of Employment Protection? The Case of the Americans with Disabilities Act." Journal of Political Economy 109 (5): 915-957.

Adam, Stuart, and Antoine Bozio, and Carl Emmerson. 2010. "Reforming Disability Insurance in the UK: Evaluation of the Pathways to Work Programme." mimeo.

Arellano, F. Alfonso. 2005. "Evaluating the Effects of Labour Market Reforms at the Margin on Unemployment and Employment Stability: The Spanish Case." UC3M Working Paper 05-12.

Autor, David H., and Mark G. Duggan. 2003. "The Rise in the Disability Rolls and the Decline in Unemployment." Quarterly Journal of Economics 118 (1): 157-206.

Autor, David H., and Mark G. Duggan. 2006. "The Growth in the Social Security Disability Rolls: A Fiscal Crisis Unfolding." Journal of Economic Perspectives 20 (3): 71-96.

Baert, Stijn. 2016. "Wage Subsidies and Hiring Chances for the Disabled: Some Causal Evidence." The European Journal of Health Economics 17 (1): 71-86.

Benítez-Silva, Hugo, and Moshe Buchinsky, and John Rust. 2010. "Induced Entry Effects of a 1 for 2 Offset in SSDI Benefits." mimeo.

Bentolila, Samuel, and Giuseppe Bertola. 1990. "Firing costs and labour demand: How bad is Eurosclerosis?." The Review of Economic Studies 57 (3): 813-402.

Bentolila, Samuel, and Gilles Saint-Paul. 1994. "A model with labor demand with linear adjustment costs." Labour Economics 1 (3-4): 303-326.

Bertrand, Marianne, and Esther Duflo and Sendhil Mullainathan. 2004. "How Much Should We Trust Differences-in-Differences Estimates?" Quarterly Journal of Economics 119 (1): 249-275.

Burtless, Gary. 1985. "Are Targeted Wage Subsidies Harmful? Evidence from a Wage Voucher Experiment." ILR Review 39 (1): 105-114.

Datta Gupta, Nabanita, and Mona Larsen. 2010. "Evaluating Labour Market Effects of Wage Subsidies for the Disabled - the Danish Flexjob Scheme." SFI Working Paper 07:2010.

Datta Gupta, Nabanita, and Mona Larsen, and Lars Stage Thomsen. 2015. "Do Wage Subsidies for Disabled Workers Reduce their Non-employment? - Evidence from the Danish Flexjob Scheme." IZA Journal of Labour Policy 4 (10).

De Jong, Philip, and Maarten Lindeboom, and Bas van der Klaauw. 2011. "Screening Disability Insurance Applications." Journal of the European Economic Association 9 (1): 106-129.

DeLeire, Thomas. 2000. "The Wage and Employment Effects of the Americans with Disabilities Act." The Journal of Human Resources 35 (4): 693-715.

Deuchert, Eva, and Lukas Kauer. 2013. "Hiring Subsidies for People with a Disability: Helping or Hindering? - Evidence from a Small Scale Social Field Experiment." Working Paper. University of St. Gallen, School of Economics and Political Science.

García Pérez, J. Ignacio, and Ioana Marinescu, and Judit Vall Castelló. 2018. "Can Fixed-term contracts put low skilled youth in a better career path? Evidence from Spain" Economic Journal DOI: https://doi.org/10.1111/ecoj.12621.

García Pérez, J. Ignacio, and Yolanda F. Rebollo Sanz. 2009. "The Use of Permanent Contracts Across Spanish Regions: Do Regional Wage Subsidies Work?” Investigaciones Económicas 33 (1): 97-130. 
Gruber, Jonathan, and Jeffrey D. Kubik. 1997. "Disability Insurance Rejection Rates and the Labour Supply of Older Workers." Journal of Public Economics 64 (1): 1-23.

Hernanz, Virginia, and Juan F. Jimeno, and Adriana Kugler. 2003. "Employment Consequences of Restrictive Permanent Contracts: Evidence from Spanish Labour Market Reforms." CEPR Discussion Paper No. 3724.

Jiménez-Martín, Sergi, and Arnau Juanmarti Mestres, and Judit Vall Castelló. 2016. "Great Recession and Disability Insurance in Spain." Barcelona GSE Working Paper 896.

Johansson, Per, and Lisa Laun and Tobias Laun. 2014. "Screening Stringency in the Disability Insurance Program." The B.E. Journal of Economic Analysis \& Policy 14 (3): 873-891.

Kostol, Andreas Ravndal, and Magne Mogstad. 2014. "How Financial Incentives Induce Disability Insurance Recipients to Return to Work." American Economic Review 104 (2): 624-55.

Koning, Pierre, and Maarten Lindeboom. 2015. "''The Rise and Fall of Disability Insurance Enrollment in the Netherlands." Journal of Economic Perspectives 29 (2): 151-72.

Marie, Olivier, and Judit Vall Castelló. 2012. "Measuring the (Income) Effect of Disability Insurance Generosity on Labour Market Participation." Journal of Public Economics 96 (1-2): 198-210.

Moffitt, Robert, and Hilary Williamson Hoynes. 1999. "Tax Rates and Work Incentives in the Social Security Disability Insurance Program: Current Law and Alternative Reforms." National Tax Journal 52 (4): 623-654.

Organisation for Economic Co-operation and Development. 2003. "Transforming Disability into Ability: Policies to Promote Work and Income Security for Disabled People." Paris: OECD.

Organisation for Economic Co-operation and Development. 2010. "Sickness, Disability and Work: Breaking the Barriers: A Synthesis of Findings across OECD Countries." OECD Publishing.

Sestito, Paolo, and Eliana Viviano. 2018. "Firing costs and firm hiring: Evidence from an Italian reform." Economic Policy 33 (93): 101-130.

Skedinger, Per. 2011. "Employment Consequences of Employment Protection Legislation." IFN Working Paper No. 865.

Staubli, Stefan. 2011. "The Impact of Stricter Criteria for Disability Insurance on Labor Force Participation." Journal of Public Economics 95 (9-10): 1223-1235.

Vall Castelló, Judit. 2012. "Promoting Employment of Disabled Women in Spain; Evaluating a Policy." Labour Economics 19 (1): 82-91. 
Figures And TAbles

\section{Figure 1-Timing of Implementation of HiRing Subsidies AmONG The 17 REGIONS IN SPAIN}

(A) Subsidies For Permanent

EMPLOYMENT

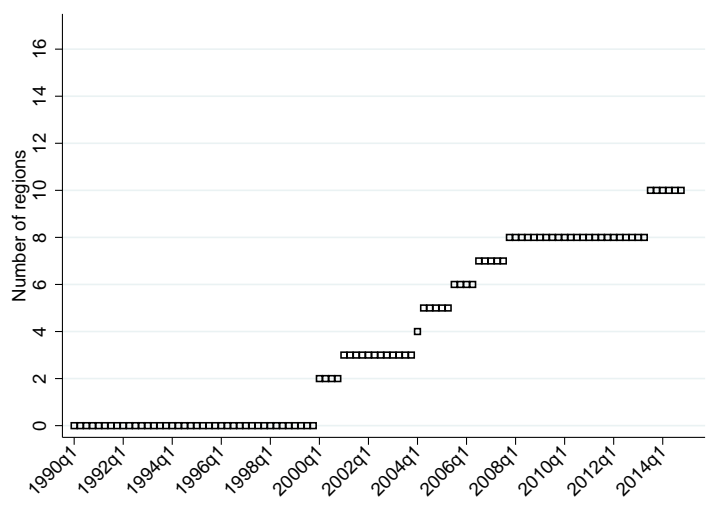

(B) SUbSIDIES FOR TEMPORARY

EMPLOYMENT

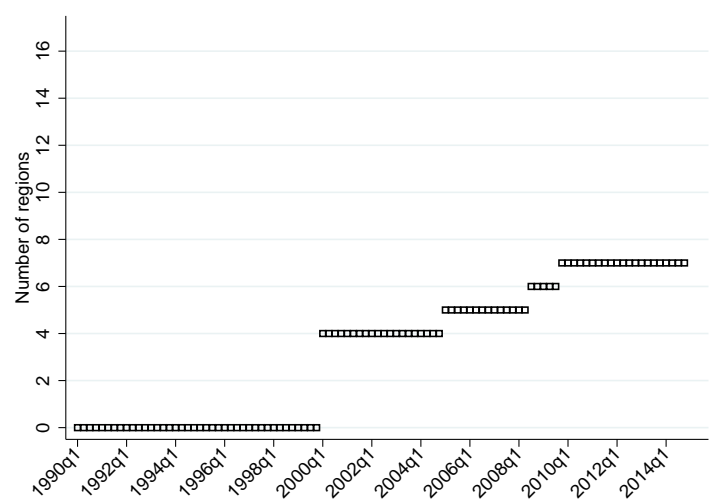

(C) SubSidies For CONVERSiOnS

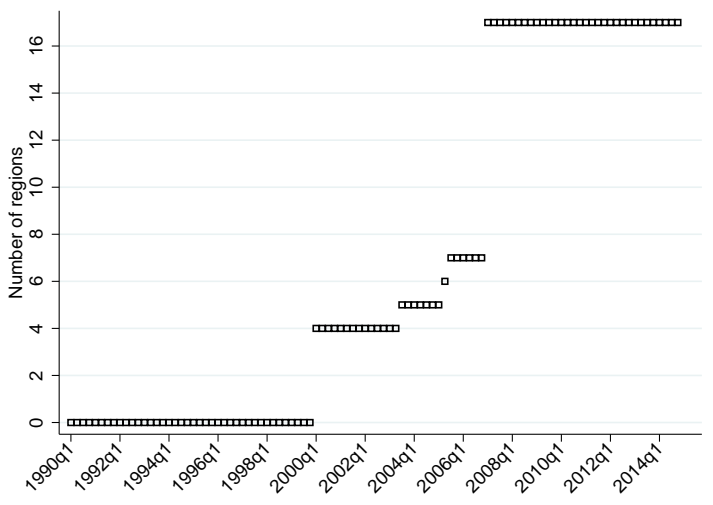

Notes: For each type of hiring subsidy, the figure shows a time series of the number of regions in which the subsidy scheme is available (out of the 17 regions in Spain). In the case of hiring subsidies for permanent employment, because the subsidy is implemented at the national level during all of our study period, the figure shows the number of regions that implement a subsidy with a higher amount than the subsidy implemented at the national level. 
Figure 2-Amount of HiRing SubSidies

(A) Subsidies For Permanent

EMPLOYMENT

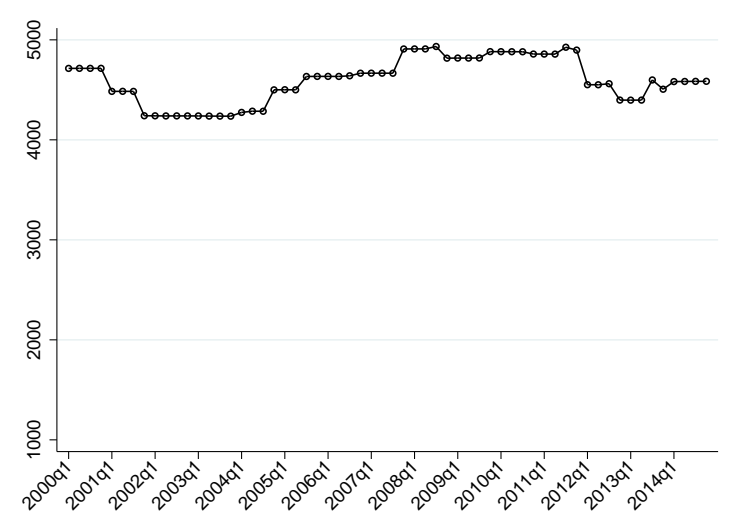

(B) SUBSIDIES FOR TEMPORARY

EMPLOYMENT

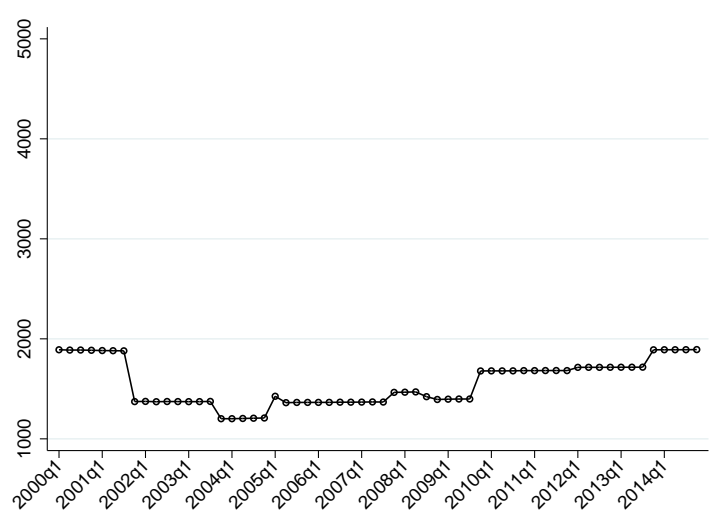

(C) SUbSidies FOR CONVERSIONS

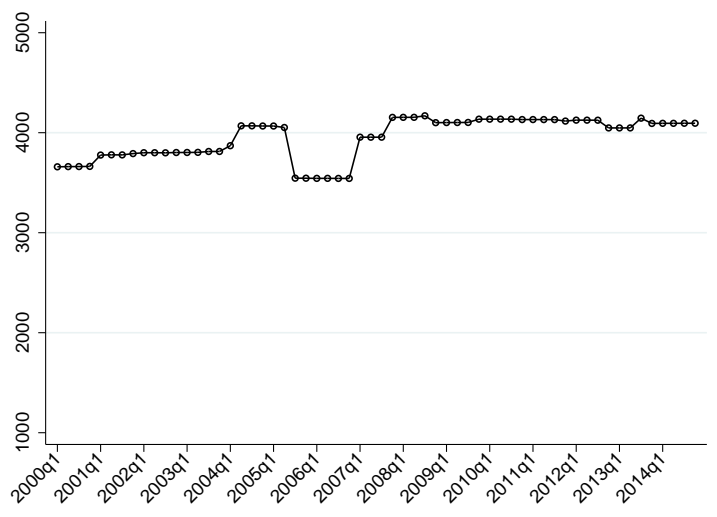

Notes: For each type of hiring subsidy, the figure shows the average amount of the subsidy scheme among the regions that implement the subsidy in each time period. 
Figure 3-Amount of Hiring Subsidies as a Percentage of Wages

(A) Subsidies For Permanent

EMPLOYMENT

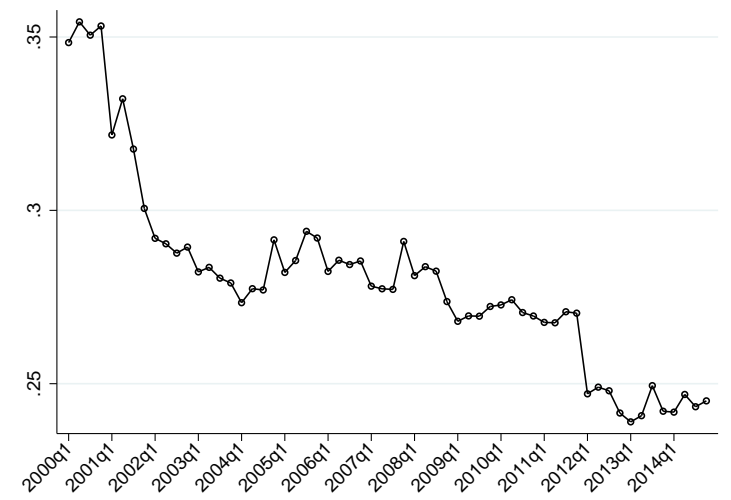

(B) SUBSIDIES FOR TEMPORARY

EMPLOYMENT

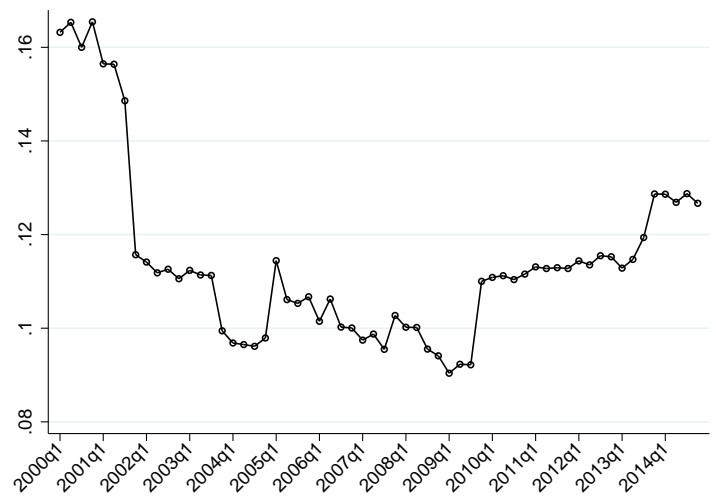

(C) SUbSidies FOR CONVERSIONS

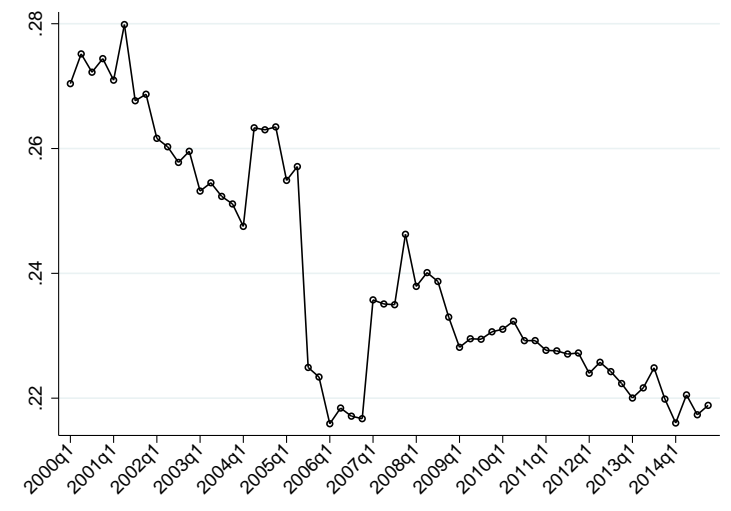

Notes: For each type of hiring subsidy, the figure shows the average amount of the subsidy among the regions that implement the subsidy in each time period, expressed as a percentage of the disabled's mean annual wage in each time period. The mean annual wage is computed for permanent employees in subfigures (a) and (c) and for temporary employees in subfigure (b). Wages refer to the mean contributory bases of employees in our samples of study. 
Figure 4-Length of Employment Protection Among Regions

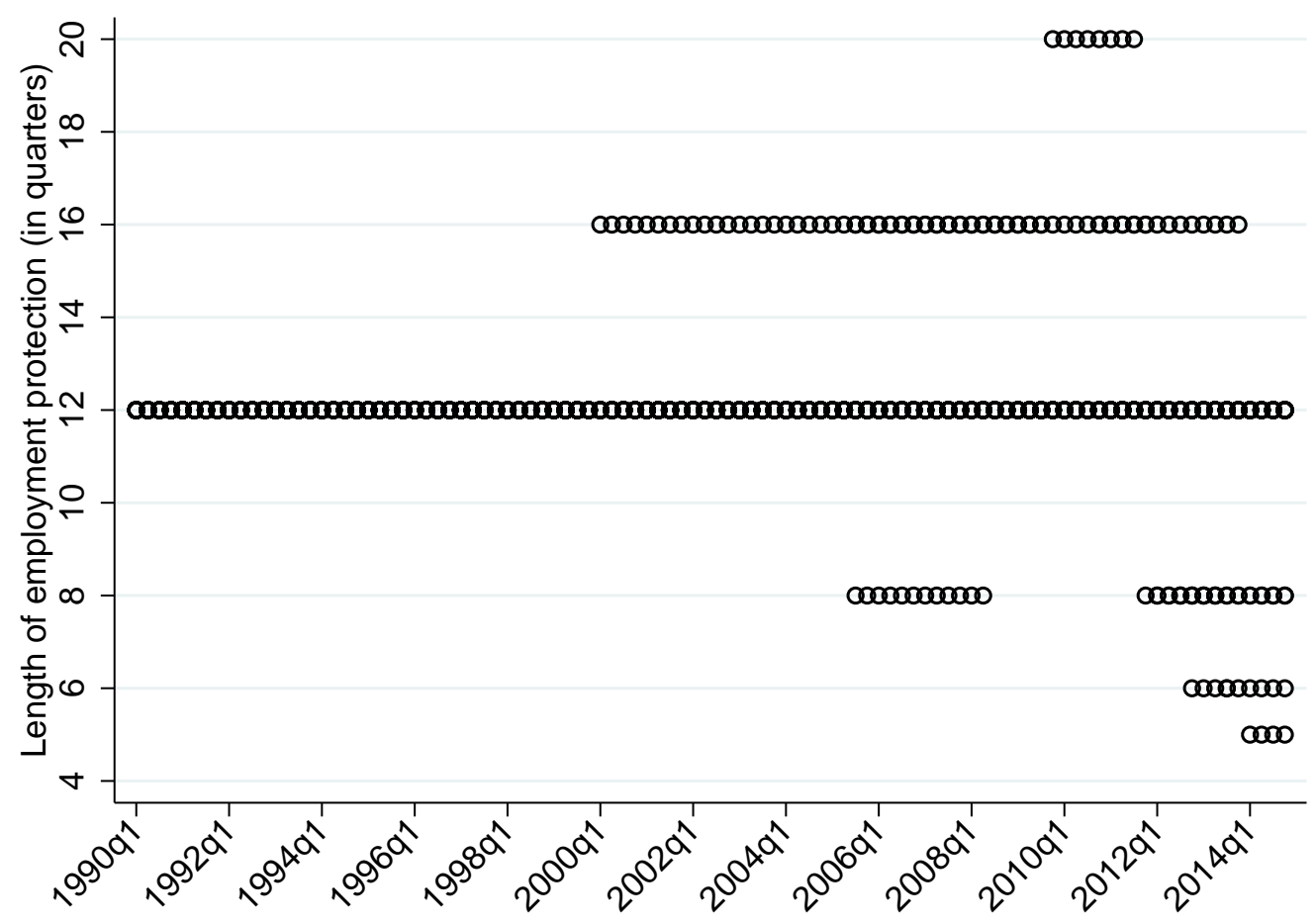

Notes: The figure shows, for every observed quarter, the variation in the number of quarters of protection associated with the subsidy scheme over Spanish regions. Quarters of protection refer to the number of quarters the employer has to maintain the subsidized worker in employment if hired in a permanent basis. The dots represent the number of quarters of protection in place at that particular quarter taking into account all regional variation across Spain. It does not show, however, the number of regions implementing them as the aim of the picture is to show the variation of this variable at each moment during our sample period 


\section{Figure 5-OBSERVED TRANSITIONS From UnEMPLOYMENT TO EMPLOYMENT}

(A) NATIONAL TRENDS

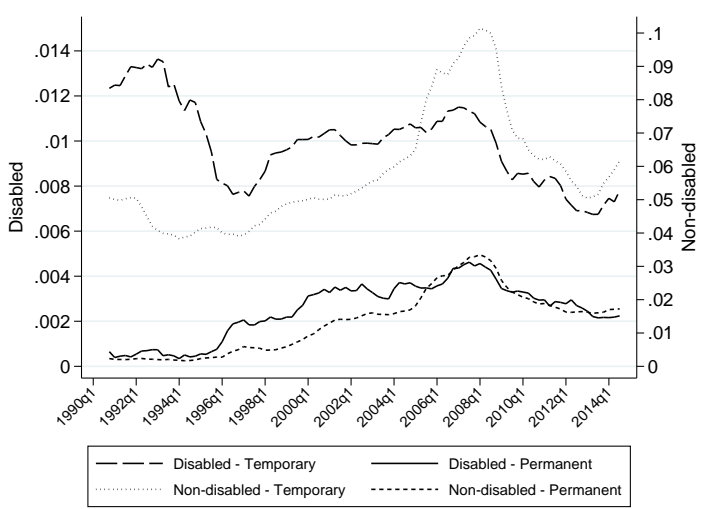

(B) REGIONAL VARIATION
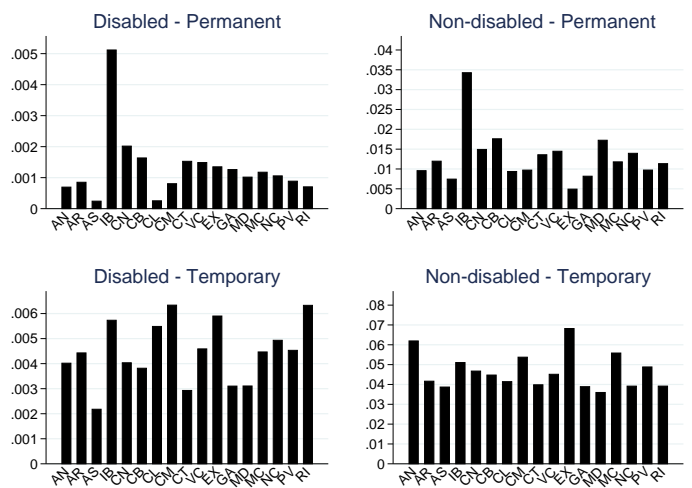

Notes: Figure 5.A shows a time series of the transition rates from unemployment to both temporary and permanent employment for disabled and non-disabled individuals during our analysis period. Figure 5.B shows the same transition rates differentiated by Spanish regions in the year 2014.

\section{Figure 6-Observed CONVERSiOns From TEMPORARY to PERMANEnT}

\section{EMPLOYMENT}

(A) NATIONAL TRENDS

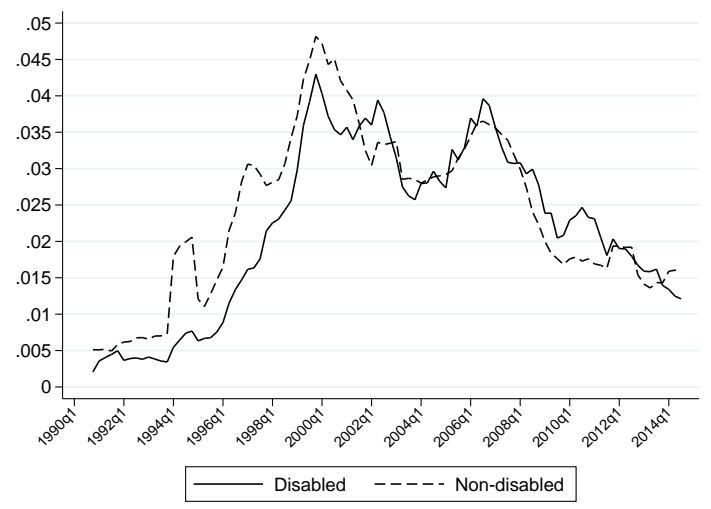

(B) REGIONAL VARIATION

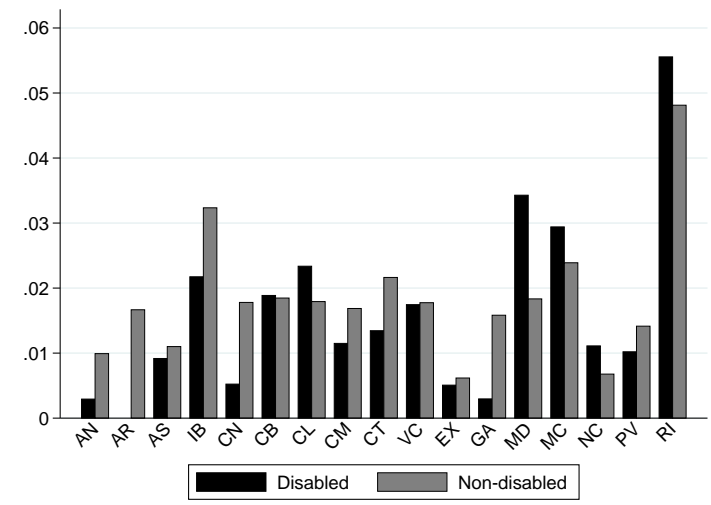

Notes: Figure 6.A shows a time series of the conversion rate from temporary to permanent employment for disabled and non-disabled individuals during our analysis period. Figure 6.B shows the same conversion rate differentiated by Spanish regions in the year 2014. 
TABLE 1 -DESCRIPTION OF COVARIATES

\begin{tabular}{|c|c|}
\hline Covariate & Description \\
\hline Women & Indicator for women. \\
\hline Total disability & $\begin{array}{l}\text { Indicator for individuals with a degree of disability classified by the Social Security as } \\
\text { "Total disability". The rest of individuals have a degree classified as "Partial Disabil- } \\
\text { ity". Degrees are assigned by the Social Security depending on the reduction in working } \\
\text { capacity caused by the disability. }\end{array}$ \\
\hline Age 50-64 & Indicator for older individuals (ages 50-64). \\
\hline High skill & $\begin{array}{l}\text { Indicator for high skilled individuals (constructed from Social Security contributory } \\
\text { groups). }\end{array}$ \\
\hline Services sector & Indicator for services sector. \\
\hline Replacement Rate & Ratio between DI benefit and previous wage. \\
\hline Quarters disabled & Number of quarters individual has been receiving DI benefits. \\
\hline Labor market experience & Years the individual has been in the labor market. \\
\hline Unemployment Rate & Unemployment rate for each region and time period. \\
\hline Disability contract ${ }^{(\mathrm{a})}$ & Indicator for the possession of a contract type that recognizes the disability condition. \\
\hline Contract experience ${ }^{(a)}$ & Years the individual has been in the current employment contract. \\
\hline Company’s size ${ }^{(a)}$ & $\begin{array}{l}\text { Dummy variables indicating the number of employees in the company (less than } 50 \text {, be- } \\
\text { tween } 50 \text { and } 199 \text { and more than 199). }\end{array}$ \\
\hline
\end{tabular}

(a) Variable is only included in the model estimated on the sample of temporary employees

Notes: In the sample of unemployed, variables that capture employment information (high skill, services, replacement rate) recover information from the most recent employment spell of the individual. 
TABLE 2-DESCRIPTIVE STATISTICS

\begin{tabular}{|c|c|c|c|c|c|c|}
\hline \multirow[b]{2}{*}{ Variable } & \multicolumn{2}{|c|}{$\begin{array}{c}\text { Sample of } \\
\text { Unemployed }\end{array}$} & \multicolumn{2}{|c|}{$\begin{array}{c}\text { Sample of Temporary } \\
\text { Employees }\end{array}$} & \multicolumn{2}{|c|}{$\begin{array}{c}\text { Sample of } \\
\text { Non-disabled }\end{array}$} \\
\hline & Mean & St. Dev. & Mean & St. Dev. & Mean & St. Dev. \\
\hline Women & 0.33 & 0.47 & 0.17 & 0.38 & 0.40 & 0.49 \\
\hline Total disability & 0.38 & 0.49 & 0.11 & 0.31 & & \\
\hline Ages 50-64 & 0.69 & 0.46 & 0.38 & 0.49 & 0.22 & 0.42 \\
\hline High skill & 0.76 & 0.43 & 0.72 & 0.45 & 0.70 & 0.46 \\
\hline Services sector & 0.59 & 0.49 & 0.67 & 0.47 & 0.65 & 0.48 \\
\hline Replacement rate $>1$ & 0.45 & 0.50 & 0.20 & 0.40 & & \\
\hline Quarters disabled & 23.91 & 20.98 & 30.46 & 28.85 & & \\
\hline Labor market experience & 2.76 & 0.60 & 2.77 & 0.53 & 2.18 & 1.00 \\
\hline Unemployment Rate & 17.92 & 8.19 & 17.43 & 7.96 & & \\
\hline Disability contract ${ }^{(a)}$ & & & 0.09 & 0.29 & & \\
\hline Contract experience ${ }^{(a)}$ & & & 2.24 & 3.87 & & \\
\hline Less than 49 employees $^{(a)}$ & & & 0.24 & 0.42 & & \\
\hline Between 50 and 199 employees $^{(a)}$ & & & 0.13 & 0.34 & & \\
\hline More than 199 employees $^{(a)}$ & & & 0.25 & 0.43 & & \\
\hline Observations & \multicolumn{2}{|c|}{$1,170,894$} & \multicolumn{2}{|c|}{66,579} & \multicolumn{2}{|c|}{$5,646,966$} \\
\hline
\end{tabular}

(a) Variable is only included in the model estimated on the sample of temporary employees

Notes: In the sample of unemployed, variables that capture employment information (high skill, services, replacement rate) recover information from the most recent employment spell of the individual. 
TABle 3-EFFEct of HiRing SubSidies on TrAnsitions to EMPloyment

\begin{tabular}{|c|c|c|c|c|c|c|}
\hline \multirow[b]{3}{*}{ Hiring subsidies } & \multicolumn{2}{|c|}{$\begin{array}{c}\text { (1) } \\
\text { Subsidies for Permanent Employment }\end{array}$} & \multicolumn{2}{|c|}{$\begin{array}{c}(2) \\
\text { Subsidies for Temporary Employment }\end{array}$} & \multicolumn{2}{|c|}{$\begin{array}{c}\text { (3) } \\
\text { Subsidies for Conversions }\end{array}$} \\
\hline & \multirow[t]{2}{*}{ To TE } & \multirow[t]{2}{*}{ To PE } & \multirow[t]{2}{*}{ To TE } & \multirow[t]{2}{*}{ To PE } & \multirow[t]{2}{*}{ To PE } & \multirow[t]{2}{*}{ To U } \\
\hline & & & & & & \\
\hline RRR & 0.96935 & 1.00052 & 1.07457 & 1.16518 & 0.90324 & 0.92832 \\
\hline St. Error & $(0.02673)$ & $(0.10802)$ & $(0.08685)$ & (0.17294) & $(0.07340)$ & (0.09110) \\
\hline Marginal Effect & $-3.09 \%$ & $0.06 \%$ & $7.30 \%$ & $15.96 \%$ & $-8.48 \%$ & $-5.73 \%$ \\
\hline \multicolumn{7}{|l|}{ Quarters of protection } \\
\hline RRR & $1.01087 * * *$ & 0.98454 & $1.00910^{* *}$ & $0.98430^{*}$ & 1.03118 & 1.00394 \\
\hline St. Error & $(0.00415)$ & $(0.01127)$ & $(0.00432)$ & $(0.00883)$ & $(0.02413)$ & $(0.00686)$ \\
\hline Marginal Effect & $1.08 \%$ & $-1.56 \%$ & $0.91 \%$ & $-1.58 \%$ & $2.93 \%$ & $0.25 \%$ \\
\hline \multicolumn{7}{|l|}{ Constant } \\
\hline RRR & $0.03532 * * *$ & $0.00074 * * *$ & $0.03611^{* * *}$ & $0.00073^{* * *} *$ & $0.00293 * * *$ & $0.38468 * * *$ \\
\hline St. Error & $(0.00592)$ & $(0.00026)$ & $(0.00593)$ & $(0.00025)$ & $(0.00260)$ & $(0.07261)$ \\
\hline Observations & $1,170,894$ & $1,170,894$ & $1,170,894$ & $1,170,894$ & 66,579 & 66,579 \\
\hline $\mathrm{N}^{\circ}$ of individuals & 44,780 & 44,780 & 44,780 & 44,780 & 9,373 & 9,373 \\
\hline
\end{tabular}

$* * * \mathrm{p}<0.01, * * \mathrm{p}<0.05, * \mathrm{p}<0.1$

Notes: TE $\equiv$ Temporary Employment; $\mathrm{PE} \equiv$ Permanent Employment; $\mathrm{U} \equiv$ Unemployment. Regressions are estimated using a multinomial logit approach, modeling the transition rate from the base category (unemployment in columns 1 and 2, temporary employment in column 3 ) to the indicated competing alternatives. Standard errors (in parenthesis) are clustered at the region level. Regressions include fixed effects at the year level, fixed effects at the region level, region specific linear time trends and a dummy for each quarter of the year. They also include the set of time-varying individual covariates described in Table 1. The table shows the effect on the relative risk ratio as well as the marginal effect. The relative risk ratio refers to the ratio between the indicated transition probability and the probability of remaining in the base category. The marginal effect shows the change in the actual predicted transition rate to each of the indicated alternatives, expressed as a percentage increase. In the case of the subsidy variable, the marginal effect refers to the percentage increase in the corresponding transition rate that results from the introduction of the subsidy scheme. In the case of the quarters of protection, the marginal effect refers to the percentage increase in the respective transition rate that results from an additional quarter of protection. 


\section{TABle 4-EFfect of Disability CONTRACt on Transition From PERMAnent EMPLOYMENT TO UNEMPLOYMENT}

\begin{tabular}{lc}
\hline \hline Disability contract & $\begin{array}{c}-0.03532 * * * \\
(0.00444)\end{array}$ \\
Constant & $0.11668^{* * *}$ \\
& $(0.01536)$ \\
& \\
Observations & 117,415 \\
$\mathrm{~N}^{\mathrm{o}}$ of individuals & 11,734 \\
$\mathrm{R}$-squared & 0.2628 \\
\hline
\end{tabular}

*** $\mathrm{p}<0.01, * * \mathrm{p}<0.05, * \mathrm{p}<0.1$

Notes: Regression is estimated using a linear probability model, where the dependent variable is a dummy variable equal to 1 if the individual transits from permanent employment to unemployment. Standard errors (in parenthesis) are clustered at the region level. Regression includes fixed effects at the year level, fixed effects at the region level, region specific linear time trends and a dummy for each quarter of the year. It also includes the same set of time-varying individual covariates as the ones for the model of temporary employees described in Table 1. 


\section{TABle 5-EFfect of Hiring Subsidies on Transition to Disability}

INSURANCE

\begin{tabular}{|c|c|c|c|}
\hline & (1) & (2) & (3) \\
\hline & $\begin{array}{c}\text { Subsidies for Permanent } \\
\text { Employment }\end{array}$ & $\begin{array}{c}\text { Subsidies for Temporary } \\
\text { Employment }\end{array}$ & Subsidies for Conversions \\
\hline Hiring subsidies & $\begin{array}{l}0.04405 \\
(0.03375)\end{array}$ & $\begin{array}{c}0.06010 \\
(0.05256)\end{array}$ & $\begin{array}{l}0.06549 * * \\
(0.02527)\end{array}$ \\
\hline Quarters of protection & $\begin{array}{c}0.00374 \\
(0.00218)\end{array}$ & $\begin{array}{c}0.00597 \\
(0.00347)\end{array}$ & $\begin{array}{l}0.00446^{*} \\
(0.00211)\end{array}$ \\
\hline Constant & $\begin{array}{c}0.10073 \\
(0.10898)\end{array}$ & $\begin{array}{c}0.03467 \\
(0.12353)\end{array}$ & $\begin{array}{c}0.06237 \\
(0.11073)\end{array}$ \\
\hline Observations & $5,646,966$ & $5,646,966$ & $5,646,966$ \\
\hline $\mathrm{N}^{\mathrm{o}}$ individuals & 103,564 & 103,564 & 103,564 \\
\hline R-squared & 0.00114 & 0.00114 & 0.00114 \\
\hline
\end{tabular}

$* * * \mathrm{p}<0.01, * * \mathrm{p}<0.05, * \mathrm{p}<0.1$

Notes: Regressions are estimate using a linear probability model. Coefficients are scaled to represent the change in the number of transitions to DI per 1000 individuals. Standard errors (in parenthesis) are clustered at the region level. Regressions include fixed effects at the year level, fixed effects at the region level, region specific linear time trends and a dummy for each quarter of the year. They also include the set of time-varying individual covariates described in Table 1 . 
A PPENDIX 
TABle A1-EFFect of Hiring Subsidies on Transitions to EMPloyment, By AGE GROUP

\begin{tabular}{|c|c|c|c|c|c|c|}
\hline & \multicolumn{2}{|c|}{$\begin{array}{c}\text { (1) } \\
\text { Subsidies for Permanent Employment }\end{array}$} & \multicolumn{2}{|c|}{$\begin{array}{c}\text { (2) } \\
\text { Subsidies for Temporary Employment }\end{array}$} & \multicolumn{2}{|c|}{$\begin{array}{c}\text { (3) } \\
\text { Subsidies for Conversions }\end{array}$} \\
\hline & \multirow[t]{2}{*}{ To TE } & To PE & To TE & To PE & To PE & To U \\
\hline \multicolumn{6}{|c|}{ Panel A: Ages 16-35 } & \\
\hline \multicolumn{7}{|l|}{ Hiring subsidies } \\
\hline RRR & 0.99456 & 0.88117 & 1.02299 & 1.18380 & 1.40601 & 1.14498 \\
\hline St. Error & $(0.09355)$ & $(0.15334)$ & $(0.11445)$ & $(0.27135)$ & $(0.30859)$ & $(0.18173)$ \\
\hline Marginal Effect & $-0.47 \%$ & $-12.26 \%$ & $2.16 \%$ & $17.61 \%$ & $30.68 \%$ & $9.93 \%$ \\
\hline \multicolumn{7}{|l|}{ Quarters of protection } \\
\hline RRR & $1.02320^{*}$ & 1.00875 & $1.02303^{* *}$ & 1.00224 & $0.90266^{*}$ & 0.98447 \\
\hline St. Error & $(0.01226)$ & $(0.01911)$ & $(0.01136)$ & $(0.01555)$ & $(0.05165)$ & $(0.02138)$ \\
\hline Marginal Effect & $2.24 \%$ & $0.82 \%$ & $2.23 \%$ & $0.18 \%$ & $-9.66 \%$ & $-0.99 \%$ \\
\hline \multicolumn{7}{|l|}{ Constant } \\
\hline RRR & $0.01764 * * *$ & $0.00032^{* * *}$ & $0.01762 * * *$ & $0.00036^{* * *}$ & $0.00684 * * *$ & 0.57929 \\
\hline St. Error & $(0.00956)$ & $(0.00033)$ & $(0.00982)$ & $(0.00034)$ & $(0.01131)$ & $(0.34792)$ \\
\hline Observations & 64,528 & 64,528 & 64,528 & 64,528 & 10,363 & 10,363 \\
\hline $\mathrm{N}^{\circ}$ of individuals & 4,954 & 4,954 & 4,954 & 4,954 & 1,476 & 1,476 \\
\hline \multicolumn{7}{|c|}{ Panel B: Ages 36-50 } \\
\hline \multicolumn{7}{|l|}{ Hiring subsidies } \\
\hline RRR & $0.89346^{* *}$ & 0.90147 & 1.08028 & 1.26875 & $0.81333^{*}$ & 0.84796 \\
\hline St. Error & $(0.04620)$ & $(0.13663)$ & $(0.13551)$ & $(0.29804)$ & $(0.09554)$ & $(0.11686)$ \\
\hline Marginal Effect & $-10.95 \%$ & $-10.09 \%$ & $7.74 \%$ & $25.38 \%$ & $-17.24 \%$ & $-12.99 \%$ \\
\hline \multicolumn{7}{|l|}{ Quarters of protection } \\
\hline RRR & $1.01164 * *$ & 0.98816 & 1.00558 & 0.98306 & $1.05943^{* * *}$ & 1.00665 \\
\hline St. Error & $(0.00587)$ & $(0.01042)$ & $(0.00703)$ & $(0.01216)$ & $(0.02108)$ & $(0.00684)$ \\
\hline Marginal Effect & $1.15 \%$ & $-1.20 \%$ & $0.56 \%$ & $-1.71 \%$ & $5.52 \%$ & $0.41 \%$ \\
\hline \multicolumn{7}{|l|}{ Constant } \\
\hline RRR & $0.01361 * * *$ & $0.00006^{* * *}$ & $0.01532 * * *$ & $0.00006^{* * *}$ & $0.00158^{* * *}$ & 0.71432 \\
\hline St. Error & $(0.00305)$ & $(0.00005)$ & $(0.00362)$ & $(0.00006)$ & $(0.00153)$ & $(0.16309)$ \\
\hline Observations & 333,346 & 333,346 & 333,346 & 333,346 & 33,844 & 33,844 \\
\hline $\mathrm{N}^{\mathrm{o}}$ of individuals & 18,457 & 18,457 & 18,457 & 18,457 & 4,636 & 4,636 \\
\hline \multicolumn{7}{|c|}{ Panel C: Ages 51-64 } \\
\hline \multicolumn{7}{|l|}{ Hiring subsidies } \\
\hline RRR & $1.11035^{*}$ & $1.37153^{* *}$ & 1.10328 & 0.90656 & 0.77733 & 0.93604 \\
\hline St. Error & $(0.06355)$ & $(0.18748)$ & $(0.17176)$ & $(0.31981)$ & $(0.14131)$ & $(0.07928)$ \\
\hline Marginal Effect & $10.60 \%$ & $33.27 \%$ & $10.10 \%$ & $-9.57 \%$ & $-23.76 \%$ & $-4.85 \%$ \\
\hline \multicolumn{7}{|l|}{ Quarters of protection } \\
\hline RRR & 1.00332 & 0.97083 & 1.00889 & 0.98414 & 1.04638 & 1.00947 \\
\hline St. Error & $(0.01257)$ & $(0.02115)$ & $(0.01458)$ & $(0.02464)$ & $(0.05602)$ & $(0.01196)$ \\
\hline Marginal Effect & $0.33 \%$ & $-2.96 \%$ & $0.89 \%$ & $-1.60 \%$ & $4.27 \%$ & $0.68 \%$ \\
\hline \multicolumn{7}{|l|}{ Constant } \\
\hline RRR & $0.00832 * * *$ & $0.00030^{* * *}$ & $0.00730^{* * *}$ & $0.00022 * * *$ & $0.00308^{* * *}$ & 0.82739 \\
\hline St. Error & $(0.00370)$ & $(0.00028)$ & $(0.00362)$ & $(0.00021)$ & $(0.00467)$ & $(0.57571)$ \\
\hline Observations & 773,020 & 773,020 & 773,020 & 773,020 & 22,372 & 22,372 \\
\hline $\mathrm{N}^{\mathrm{o}}$ of individuals & 33,822 & 33,822 & 33,822 & 33,822 & 4,565 & 4,565 \\
\hline \multicolumn{7}{|c|}{$* * * \mathrm{p}<0.01, * * \mathrm{p}<0.05, * \mathrm{p}<0.1$} \\
\hline \multicolumn{7}{|c|}{$\begin{array}{l}\text { Notes: } \mathrm{TE} \equiv \text { Temporary Employment; } \mathrm{PE} \equiv \text { Permanent Employment; } \mathrm{U} \equiv \text { Unemployment. Regressions are estimated using a multinomial logit } \\
\text { approach, modeling the transition rate from the base category (unemployment in columns } 1 \text { and 2, temporary employment in column } 3 \text { ) to the } \\
\text { indicated competing alternatives. Standard errors (in parenthesis) are clustered at the region level. Regressions include fixed effects at the year level, } \\
\text { fixed effects at the region level, region specific linear time trends and a dummy for each quarter of the year. They also include the set of time-varying } \\
\text { individual covariates described in Table } 1 \text {. The table shows the effect on the relative risk ratio as well as the marginal effect. The relative risk ratio } \\
\text { refers to the ratio between the indicated transition probability and the probability of remaining in the base category. The marginal effect shows the } \\
\text { change in the actual predicted transition rate to each of the indicated alternatives, expressed as a percentage increase. In the case of the subsidy } \\
\text { variable, the marginal effect refers to the percentage increase in the corresponding transition rate that results from the introduction of the subsidy } \\
\text { scheme. In the case of the quarters of protection, the marginal effect refers to the percentage increase in the respective transition rate that results from } \\
\text { an additional quarter of protection. }\end{array}$} \\
\hline
\end{tabular}


Table A2-EfFect of Hiring Subsidies on Transitions to Employment, BY GENDER

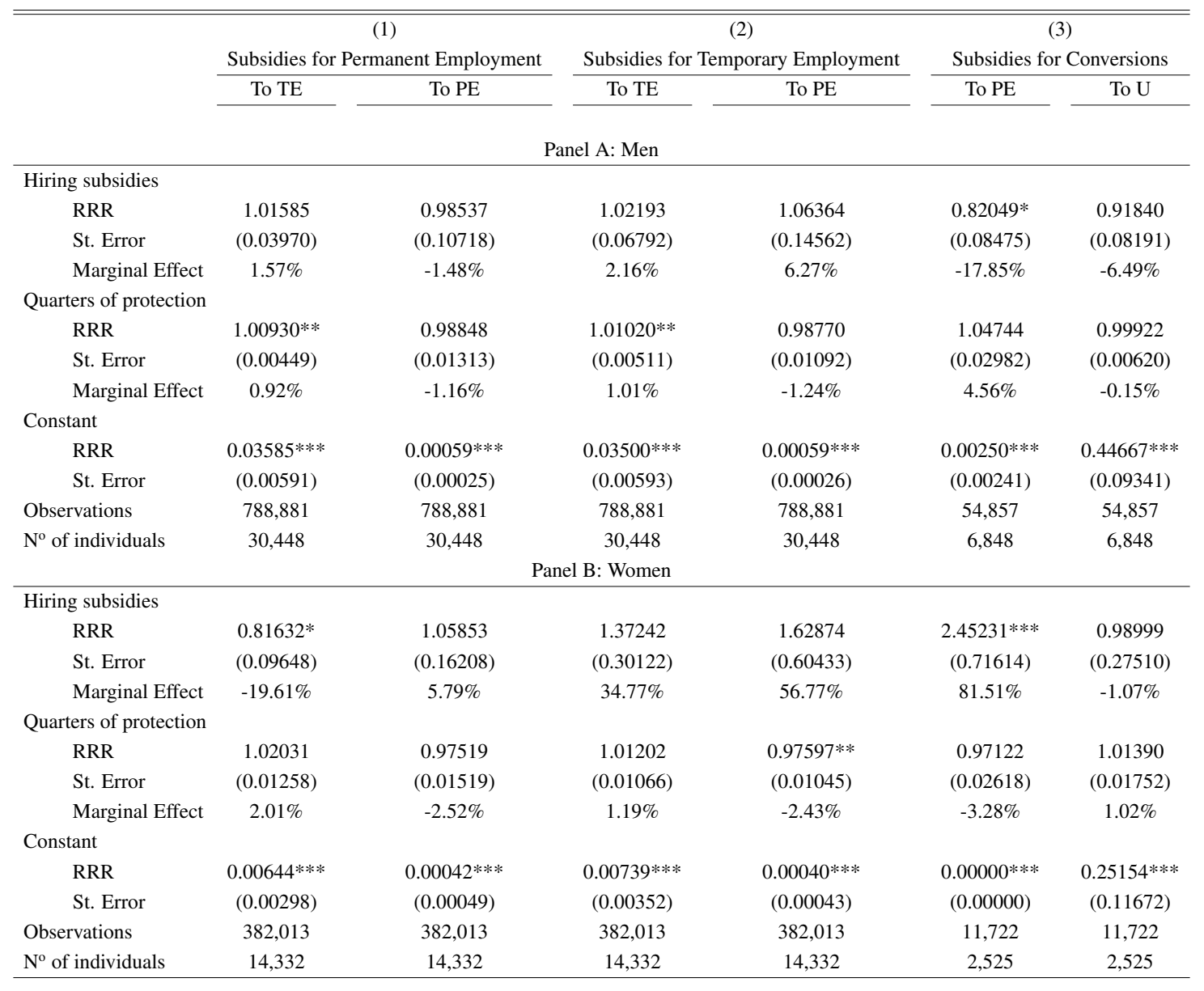

*** $\mathrm{p}<0.01, * * \mathrm{p}<0.05, * \mathrm{p}<0.1$

Notes: TE $\equiv$ Temporary Employment; $\mathrm{PE} \equiv$ Permanent Employment; $\mathrm{U} \equiv$ Unemployment. Regressions are estimated using a multinomial logit approach, modeling the transition rate from the base category (unemployment in columns 1 and 2, temporary employment in column 3 ) to the indicated competing alternatives. Standard errors (in parenthesis) are clustered at the region level. Regressions include fixed effects at the year level, fixed effects at the region level, region specific linear time trends and a dummy for each quarter of the year. They also include the set of time-varying individual covariates described in Table 1. The table shows the effect on the relative risk ratio as well as the marginal effect. The relative risk ratio refers to the ratio between the indicated transition probability and the probability of remaining in the base category. The marginal effect shows the change in the actual predicted transition rate to each of the indicated alternatives, expressed as a percentage increase. In the case of the subsidy variable, the marginal effect refers to the percentage increase in the corresponding transition rate that results from the introduction of the subsidy scheme. In the case of the quarters of protection, the marginal effect refers to the percentage increase in the respective transition rate that results from an additional quarter of protection. 


\section{TABle A3-EFfect of Hiring Subsidies on TrAnsition to DisAbility InSURANCE, By AgE GROUP}

\begin{tabular}{|c|c|c|c|}
\hline & $\begin{array}{c}\text { (1) } \\
\text { Subsidies for Permanent } \\
\text { Employment }\end{array}$ & $\begin{array}{c}(2) \\
\text { Subsidies for Temporary } \\
\text { Employment }\end{array}$ & $\begin{array}{c}\text { (3) } \\
\text { Subsidies for Conversions }\end{array}$ \\
\hline \multicolumn{4}{|c|}{ PANEL A: AGES 16-35 } \\
\hline \multirow[t]{2}{*}{ Hiring subsidies } & $0.02096 * *$ & -0.00942 & 0.00419 \\
\hline & $(0.00782)$ & $(0.02059)$ & $(0.01382)$ \\
\hline \multirow[t]{2}{*}{ Quarters of protection } & 0.00344 & $0.00460 *$ & $0.00452 *$ \\
\hline & $(0.00217)$ & $(0.00230)$ & $(0.00234)$ \\
\hline \multirow[t]{2}{*}{ Constant } & -0.01040 & -0.03181 & -0.03386 \\
\hline & $(0.04784)$ & $(0.05007)$ & $(0.05033)$ \\
\hline Observations & $2,255,326$ & $2,255,326$ & $2,255,326$ \\
\hline $\mathrm{N}^{0}$ individuals & 61,500 & 61,500 & 61,500 \\
\hline R-squared & 0.00018 & 0.00018 & 0.00018 \\
\hline \multicolumn{4}{|c|}{ Panel B: Ages $36-50$} \\
\hline \multirow[t]{2}{*}{ Hiring subsidies } & 0.05618 & 0.06722 & 0.05506 \\
\hline & $(0.03509)$ & $(0.04154)$ & $(0.03471)$ \\
\hline \multirow[t]{2}{*}{ Quarters of protection } & 0.00192 & 0.00443 & 0.00338 \\
\hline & $(0.00309)$ & $(0.00418)$ & $(0.00310)$ \\
\hline \multirow[t]{2}{*}{ Constant } & 0.04191 & -0.03616 & -0.01126 \\
\hline & $(0.16177)$ & $(0.17860)$ & $(0.17289)$ \\
\hline Observations & $2,278,634$ & $2,278,634$ & $2,278,634$ \\
\hline $\mathrm{N}^{\mathrm{o}}$ individuals & 71,014 & 71,014 & 71,014 \\
\hline R-squared & 0.00029 & 0.00029 & 0.00029 \\
\hline \multicolumn{4}{|c|}{ PANEL C: AgES 51-64 } \\
\hline \multirow[t]{2}{*}{ Hiring subsidies } & 0.08460 & 0.18931 & $0.30863 * *$ \\
\hline & $(0.18405)$ & $(0.25458)$ & $(0.13454)$ \\
\hline \multirow[t]{2}{*}{ Quarters of protection } & 0.01277 & 0.01640 & 0.01109 \\
\hline & $(0.00794)$ & $(0.00958)$ & $(0.00663)$ \\
\hline \multirow[t]{2}{*}{ Constant } & $3.30469 * * *$ & $3.15704 * * *$ & $3.24582 * * *$ \\
\hline & $(0.49162)$ & $(0.45591)$ & $(0.47396)$ \\
\hline Observations & $1,113,006$ & $1,113,006$ & $1,113,006$ \\
\hline $\mathrm{N}^{\mathrm{o}}$ individuals & 42,830 & 42,830 & 42,830 \\
\hline R-squared & 0.00062 & 0.00062 & 0.00062 \\
\hline
\end{tabular}

$* * * \mathrm{p}<0.01, * * \mathrm{p}<0.05, * \mathrm{p}<0.1$

Notes: Regressions are estimate using a linear probability model. Coefficients are scaled to represent the change in the number of transitions to DI per 1000 individuals. Standard errors (in parenthesis) are clustered at the region level. Regressions include fixed effects at the year level, fixed effects at the region level, region specific linear time trends and a dummy for each quarter of the year. They also include the set of time-varying individual covariates described in Table 1. 


\section{TABle A4-EFFect of Hiring Subsidies on Transition to DisAbility INSURANCE, BY GENDER}

\begin{tabular}{|c|c|c|c|}
\hline & $\begin{array}{c}\text { (1) } \\
\text { Subsidies for Permanent } \\
\text { Employment }\end{array}$ & $\begin{array}{c}(2) \\
\text { Subsidies for Temporary } \\
\text { Employment }\end{array}$ & $\begin{array}{c}\text { (3) } \\
\text { Subsidies for Conversions }\end{array}$ \\
\hline \multicolumn{4}{|c|}{ PANEL A: MEN } \\
\hline \multirow[t]{2}{*}{ Hiring subsidies } & $0.09928 * *$ & 0.00973 & 0.04213 \\
\hline & $(0.04037)$ & $(0.04174)$ & $(0.04027)$ \\
\hline \multirow[t]{2}{*}{ Quarters of protection } & $0.00713^{* *}$ & $0.01200 * *$ & $0.01106^{* *}$ \\
\hline & $(0.00302)$ & $(0.00554)$ & $(0.00404)$ \\
\hline \multirow[t]{2}{*}{ Constant } & -0.16330 & -0.27498 & -0.26597 \\
\hline & $(0.14601)$ & $(0.18170)$ & $(0.16501)$ \\
\hline Observations & $3,409,540$ & $3,409,540$ & $3,409,540$ \\
\hline $\mathrm{N}^{\mathrm{o}}$ individuals & 62,820 & 62,820 & 62,820 \\
\hline \multirow[t]{2}{*}{$\mathrm{R}$-squared } & 0.00115 & 0.00115 & 0.00115 \\
\hline & & : WOMEN & \\
\hline \multirow[t]{2}{*}{ Hiring subsidies } & -0.02831 & 0.13551 & 0.08894 \\
\hline & $(0.03485)$ & $(0.08223)$ & $(0.05129)$ \\
\hline \multirow[t]{2}{*}{ Quarters of protection } & -0.00074 & -0.00189 & -0.00401 \\
\hline & $(0.00328)$ & $(0.00313)$ & $(0.00275)$ \\
\hline \multirow[t]{2}{*}{ Constant } & $0.27275^{* *}$ & $0.26293^{*}$ & $0.31777 * *$ \\
\hline & $(0.11985)$ & $(0.12883)$ & $(0.13293)$ \\
\hline Observations & $2,237,426$ & $2,237,426$ & $2,237,426$ \\
\hline $\mathrm{N}^{\mathrm{o}}$ individuals & 40,744 & 40,744 & 40,744 \\
\hline R-squared & 0.00106 & 0.00106 & 0.00106 \\
\hline
\end{tabular}

$* * * \mathrm{p}<0.01, * * \mathrm{p}<0.05, * \mathrm{p}<0.1$

Notes: Regressions are estimate using a linear probability model. Coefficients are scaled to represent the change in the number of transitions to DI per 1000 individuals. Standard errors (in parenthesis) are clustered at the region level. Regressions include fixed effects at the year level, fixed effects at the region level, region specific linear time trends and a dummy for each quarter of the year. They also include the set of time-varying individual covariates described in Table 1. 
Table A5-EFfect of Hiring Subsidies on Transitions to EMPloyment. Placebo Estimates

\begin{tabular}{|c|c|c|c|c|c|c|}
\hline & \multicolumn{2}{|c|}{$\begin{array}{c}\text { (1) } \\
\text { Subsidies for Permanent Employment }\end{array}$} & \multicolumn{2}{|c|}{$\begin{array}{c}\text { (2) } \\
\text { Subsidies for Temporary Employment }\end{array}$} & \multicolumn{2}{|c|}{$\begin{array}{c}\text { (3) } \\
\text { Subsidies for Conversions }\end{array}$} \\
\hline & To TE & To PE & To TE & To PE & To PE & To U \\
\hline \multicolumn{7}{|l|}{ Hiring subsidies } \\
\hline RRR & 1.18314 & $4.93351 * * *$ & 1.05690 & 1.20070 & 1.36640 & 0.92979 \\
\hline St. Error & $(0.29297)$ & (2.41191) & $(0.28618)$ & $(0.86458)$ & $(0.45195)$ & $(0.11455)$ \\
\hline \multicolumn{7}{|c|}{ Quarters of protection } \\
\hline RRR & 0.94804 & 0.75852 & 0.98779 & 1.13053 & 0.77544 & 1.01135 \\
\hline St. Error & $(0.07264)$ & $(0.13634)$ & $(0.03451)$ & $(0.14067)$ & $(0.16755)$ & $(0.02885)$ \\
\hline \multicolumn{7}{|l|}{ Constant } \\
\hline RRR & $0.06273^{* *}$ & 0.05038 & $0.03815^{* * *}$ & $0.00032 * * *$ & 0.93898 & $0.26784 * *$ \\
\hline St. Error & $(0.07769)$ & $(0.13094)$ & $(0.03307)$ & $(0.00068)$ & (2.61416) & $(0.16241)$ \\
\hline Observations & 181,300 & 181,300 & 181,300 & 181,300 & 16,776 & 16,776 \\
\hline
\end{tabular}

$* * * \mathrm{p}<0.01, * * \mathrm{p}<0.05, * \mathrm{p}<0.1$

Notes: TE $\equiv$ Temporary Employment; PE $\equiv$ Permanent Employment; U $\equiv$ Unemployment. Regressions are estimated using a multinomial logit approach, modeling the transition rate from the base category (unemployment in columns 1 and 2, temporary employment in column 3) to the indicated competing alternatives. Standard errors (in parenthesis) are clustered at the region level. Regressions include fixed effects at the year level, fixed effects at the region level, region specific linear time trends and a dummy for each quarter of the year. They also include the set of time-varying individual covariates described in Table 1. The table shows the effect on the relative risk ratio which refers to the ratio between the indicated transition probability and the probability of remaining in the base category. We have excluded all observations after the year 2000 which is the year in which the policy begins. Therefore, we only include the period 1990-2000 when there is no regional subsidies in place. 